\title{
THE DYNAMICS OF NON-PHOTOCHEMICAL QUENCHING AND CYCLIC ELECTRON TRANSPORT IN A.THALIANA EXPOSED TO HARMONICALLY OSCILLATING LIGHT
}

\author{
Niu Yuxi ${ }^{1}$, Lazár Dušan ${ }^{2}$, Holzwarth Alfred R. ${ }^{3}$, Kramer David M. ${ }^{4}$, \\ Matsubara Shizue ${ }^{1}$, Schrey Silvia D. ${ }^{1}$, Nedbal Ladislav ${ }^{1,2,5, *}$
}

${ }^{1}$ Institute of Bio- and Geosciences/Plant Sciences (IBG-2), Forschungszentrum Jülich, Wilhelm-Johnen-Straße, D-52428 Jülich, Germany

2 Department of Biophysics, Centre of the Region Haná for Biotechnological and Agricultural Research, Faculty of Science, Palacký University, Šlechtitelů 27, 78371 Olomouc, Czech Republic

3 Department of Physics and Astronomy, Faculty of Sciences, Vrije Universiteit Amsterdam, Amsterdam, The Netherlands

${ }^{4}$ MSU-DOE Plant Research Laboratory, Michigan State University, East Lansing, MI 48824, USA

${ }^{5}$ PASTEUR, Department of Chemistry, École Normale Supérieure, Université PSL, Sorbonne Université, CNRS, 24, rue Lhomond, 75005, Paris, France

*Corresponding author: nedbal.lad@gmail.com

One sentence summary: Oscillations in Chl fluorescence and redox states of plastocyanin, P700, and ferredoxin in A.thaliana induced by sinusoidal light reveal at least two distinct types of dynamic responses that depend on the non-photochemical quenching and cyclic electron transport.

\section{Funding information:}

N.Y., S.D.S., and L.N. gratefully acknowledge the financial support by the Federal Ministry of Education and Research of Germany (BMBF) in the framework of the YESPVNIGBEN project (03SF0576A).

D.L. was supported by the European Regional Development Fund project "Plants as a tool for sustainable global development" (CZ.02.1.01/0.0/0.0/16_019/0000827).

D.L., S.M., and L.N. gratefully acknowledge the financial support by EU PathFinder project DREAM 


\section{Abstract}

Plants are often exposed in nature to light fluctuations with characteristic periods of several seconds to minutes. Photosynthetically active irradiance fluctuates typically in the range of several hundreds of $\mu \mathrm{mol}\left(\right.$ photons) $\cdot \mathrm{m}^{-}$ $2 \cdot \mathrm{s}^{-1}$. The photosynthetic regulatory networks that are necessary for minimizing damage by the dynamic load between redox reactions in fluctuating light are poorly understood. Arbitrary light fluctuations can be represented by a sum of harmonic oscillations and, to resolve the elemental components of any complex light patterns, we aimed at characterizing photosynthetic reactions in light that oscillated as an elemental sinus function. Chlorophyll fluorescence yield and optical transmission proxies of P700, plastocyanin, and ferredoxin were measured in Arabidopsis thaliana under oscillating light of various frequencies and amplitudes. The role of non-photochemical quenching (NPQ) and of cyclic electron transport around Photosystem I (CET) was studied by comparing the dynamics in wild-type plants with mutants that were deficient in NPQ (npq1 and npq4) or CET (crr2-2 and pgrl1ab).

The study revealed a highly contrasting response in the mutants compared to wild type documenting relevance of non-photochemical quenching and cyclic electron transport for the functioning of plants in a dynamic light environment. The mutants deficient in the non-photochemical quenching constituents exhibited forced oscillations of much higher amplitude than those found in the wild types. The contrast was used to identify the range of frequencies $(f<1 / 60 s)$ in which the non-photochemical quenching was highly effective. The frequencydomain analysis revealed complex resonance behaviors with the $1 / 30 \mathrm{~s}^{-1}$ and $1 / 60 \mathrm{~s}^{-1}$ frequencies that were absent in the npq4 mutant and reduced in the npq1 mutant. This contrast suggests an anomalous dynamic behavior of thylakoid acidification and PsbS-dependent feedback downregulation of Photosystem II lightharvesting at these frequencies.

The mutants incapacitated in the cyclic electron transport exhibited a distinct dynamic response. The crr2-2 mutant lacks the activity of photosynthetic NADH dehydrogenase-like complex and typically exhibits wild-typelike induction during a dark-light transition and differs in the light-to-dark relaxation in the time domain. It showed a distinct dynamic signature in oscillating light that involved both rising and declining light phases. The pgrl1ab mutant exhibited a contrasting anomalous response to oscillating light, particularly in the redox reactions involving plastocyanin, P700, and ferredoxin. These findings thus suggest a crucial role of cyclic electron transport in the dynamic properties and regulation of the plants in fluctuating irradiance.

The finding of contrasting frequency-dependent modes may explain the existence of multiple, seemingly redundant regulatory mechanisms, each presumably protecting the plant in a different frequency range. The study moreover documented that the harmonically oscillating light can serve, in addition to identifying the photosynthetic dynamics in natural fluctuating light, for revealing unique dynamic features in mutants, and, likely, for sensing plant stress. Furthermore, the sensing by harmonic forcing does not require dark-acclimation and may, thus, conveniently monitor the status of photosynthesis of plants in phenotyping platforms, in greenhouses, and in-field. 
bioRxiv preprint doi: https://doi.org/10.1101/2022.02.09.479783; this version posted February 10, 2022. The copyright holder for this preprint (which was not certified by peer review) is the author/funder. All rights reserved. No reuse allowed without permission.

\section{Abbreviations and symbols}

\begin{tabular}{|c|c|}
\hline Parameter & Description \\
\hline PAR & Photosynthetically active radiation \\
\hline LET & Linear electron transport \\
\hline CET & Cyclic electron transport \\
\hline $\mathrm{AL}$ & Actinic light \\
\hline $\mathrm{Chl}$ & Chlorophyll \\
\hline ChIF & Chlorophyll fluorescence \\
\hline DMP & Differential model plot \\
\hline $\mathrm{F}_{0}, \mathrm{Fo}_{0}^{\prime}$ & $\begin{array}{l}\text { Minimal chlorophyll fluorescence emission yield measured with the primary quinone acceptor } \\
\text { oxidized }\left(Q_{A}\right) \text { in a dark-acclimated plant }\left(F_{0}\right) \text {, or light-acclimated plant }\left(F_{0}^{\prime}\right)\end{array}$ \\
\hline $\mathrm{F}_{\mathrm{M},} \mathrm{F}_{\mathrm{M}}$ & $\begin{array}{l}\text { Maximal chlorophyll fluorescence emission yield measured with the primary quinone acceptor } \\
\text { reduced }\left(Q_{A^{-}}\right) \text {in a dark-acclimated plant }\left(F_{M}\right) \text {, or light-acclimated plant }\left(F_{M}^{\prime}\right)\end{array}$ \\
\hline $\mathrm{F}^{\prime}$ & $\begin{array}{l}\text { Chlorophyll fluorescence emission yield measured in a light-acclimated plant, usually in a } \\
\text { steady-state }\end{array}$ \\
\hline $\mathrm{Fd}$ & Ferredoxin \\
\hline $\mathrm{Fd}_{\max }$ & The optical signal corresponding to the full reduction of ferredoxin \\
\hline $\mathrm{Fd}_{\text {red }}$ & Fraction of ferredoxin in the reduced form \\
\hline ML-Fluo & Green measuring light exciting chlorophyll fluorescence \\
\hline MT & $\begin{array}{l}\text { A short, intense multiple-turnover pulse of light transiently reducing photosynthetic pathways } \\
\text { by reduction of relevant acceptors or oxidation of relevant donors. }\end{array}$ \\
\hline ML-NIR & Near-infrared light to measure transmission difference as proxies for $\mathrm{PC}, \mathrm{P} 700$, and $\mathrm{Fd}$ \\
\hline NPQ & Non-photochemical quenching \\
\hline P700 & Primary donor in the reaction center of photosystem I \\
\hline $\mathrm{P} 700_{\max }$ & The optical signal corresponding to the full oxidation of P700 \\
\hline PC & Plastocyanin \\
\hline $\mathrm{PC}_{\max }$ & The optical signal corresponding to the full oxidation of plastocyanin \\
\hline $\mathrm{PC}_{\mathrm{ox}}$ & Fraction of plastocyanin in the oxidized form \\
\hline PSI & Photosystem I \\
\hline PSII & Photosystem II \\
\hline$q_{E}$ & Energy-dependent component of the non-photochemical quenching \\
\hline $\mathrm{Y}_{1}$ & Quantum yield of photosystem I photochemistry \\
\hline$Y_{1}(\mathrm{NA})$ & $\begin{array}{l}\text { Quantum yield of non-photochemical energy dissipation in PS I due to the acceptor side } \\
\text { limitation }\end{array}$ \\
\hline$Y_{1}(\mathrm{ND})$ & Quantum yield of non-photochemical energy dissipation in PS I due to the donor side limitation \\
\hline $\mathrm{Y}_{\|}$ & Quantum yield of photosystem II photochemistry \\
\hline$Y_{\Perp}(N P Q)$ & Quantum yield of the regulated light-induced non-photochemical quenching of PSII \\
\hline $\mathrm{Y}_{11}(\mathrm{NO})$ & Quantum yield of the non-regulated constitutive non-photochemical quenching of PSII \\
\hline
\end{tabular}




\section{Introduction}

The photosynthesis of plants and algae is driven in nature by a light that often fluctuates with a wide range of characteristic frequencies and irradiance levels. The character of the fluctuations appearing in forest and crop field understories, or at the bottom layers of the photic zone in aquatic environments qualitatively differs from the fluctuations in upper plant canopies or close to the ocean surface. The frequency caused by a wind-driven leaf flutter is several orders of magnitude higher than the one caused by moving clouds or the changing sun's position in the sky relative to gaps in the vegetation. Various mechanisms leading to light fluctuations are summarized in Tab.1.

The light fluctuations instantaneously translate into fluctuations in the photosynthetic electron transport of plants. Periodic filling and emptying of the biochemical pools would, without regulation, cause dynamic damage like the one threatening the unprotected engineering systems ${ }^{1}$. Bridges can collapse, glass can break, buildings can collapse when external forces are in resonance, i.e., having the frequency equal to the frequency at which the system oscillates itself. Engineering structures are usually protected against such a dynamic load by ingenious countermeasures ${ }^{2}$. Protection of engineering systems against static and dynamic load differ and one can expect that, similarly, the mechanisms that are responsible for plant resilience to constant high light may also differ from those protecting in a fluctuating environment $3,4,5$. We shall further argue that this goes even further and that different protective mechanisms operate in different frequency domains.

To explore oscillatory behaviors in photosynthesis, we characterized the responses of photosynthetic parameters on exposure to harmonically oscillating irradiance of various frequencies ${ }^{6,7}$. This work is continued here, focusing on the role of non-photochemical quenching (NPQ) in fluctuating light. It is known that NPQ protects in excess light by alleviating overexcitation, particularly in Photosystem II where the delicate watersplitting processes take place ${ }^{8-13}$. This protection is particularly important in field conditions with fluctuating light ${ }^{14-16}$. Similar to NPQ, cyclic electron transport (CET) may play an important role in regulating electron transport and trans-thylakoid proton-motive force to protect PSI and to induce NPQ in PSII ${ }^{17-24}$. Little is known, however, about the frequency dependence of the protective NPQ and CET processes.

The tools of systems biology ${ }^{25}$ have been developed to unravel complex networks similar to those that sustain homeostasis and high-yield of plant photosynthesis in a natural fluctuating environment (Tab.1). Unraveling such complex networks requires extensive datasets characterizing plants by their systemic response to various dynamic stimuli: in the time domain, in the frequency domain, measuring multiple systems variables, and using mutants that are disabled in specific regulatory mechanisms. Here, we focus on the natural phenomena, which are classified in the bold-bordered cell in Tab.1. Towards this goal, we studied dynamics of chlorophyll fluorescence emission, and of redox changes in P700, plastocyanin, and ferredoxin appearing in Arabidopsis thaliana exposed to light that oscillated between 100 and 200, 100 and 400, and 100 and $800 \mu \mathrm{mol}$ (photons).

$2 . \mathrm{s}^{-1}$ with periods changing between $1 \mathrm{~s}$ and $8 \mathrm{~min}$. The dynamics found in the wild-type plants were compared to dynamics in mutants with disabled mechanisms of NPQ (npq1, npq4) and/or CET (crr2-2, pgrl1ab). 
Table 1. The phenomena that result in fluctuations in photosynthetically active radiation (PhAR) with different characteristic periods $T$ and frequencies $f=1 / T$ in vegetation canopies and aquatic environments.

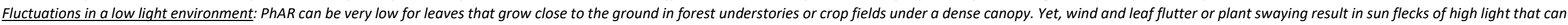

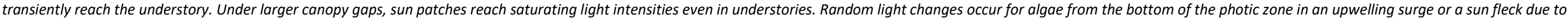
refraction at the water surface, or regular irradiance changes are caused by diurnal or tidal effects.

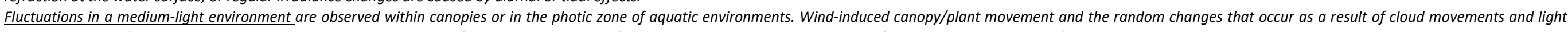

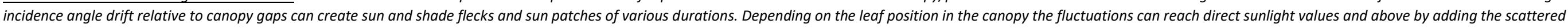
light. In aquatic environments, such enhancement over the direct sun irradiance can happen again by light focusing on the surface waves.

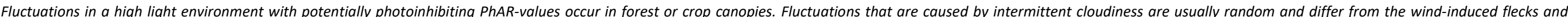

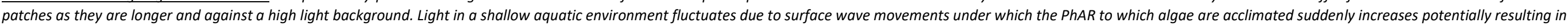
overexcitation and damage. The primary mechanism for intense fluctuations in downwelling irradiance under sunny surface conditions is the focusing and defocusing of sunlight rays refracted by waves.

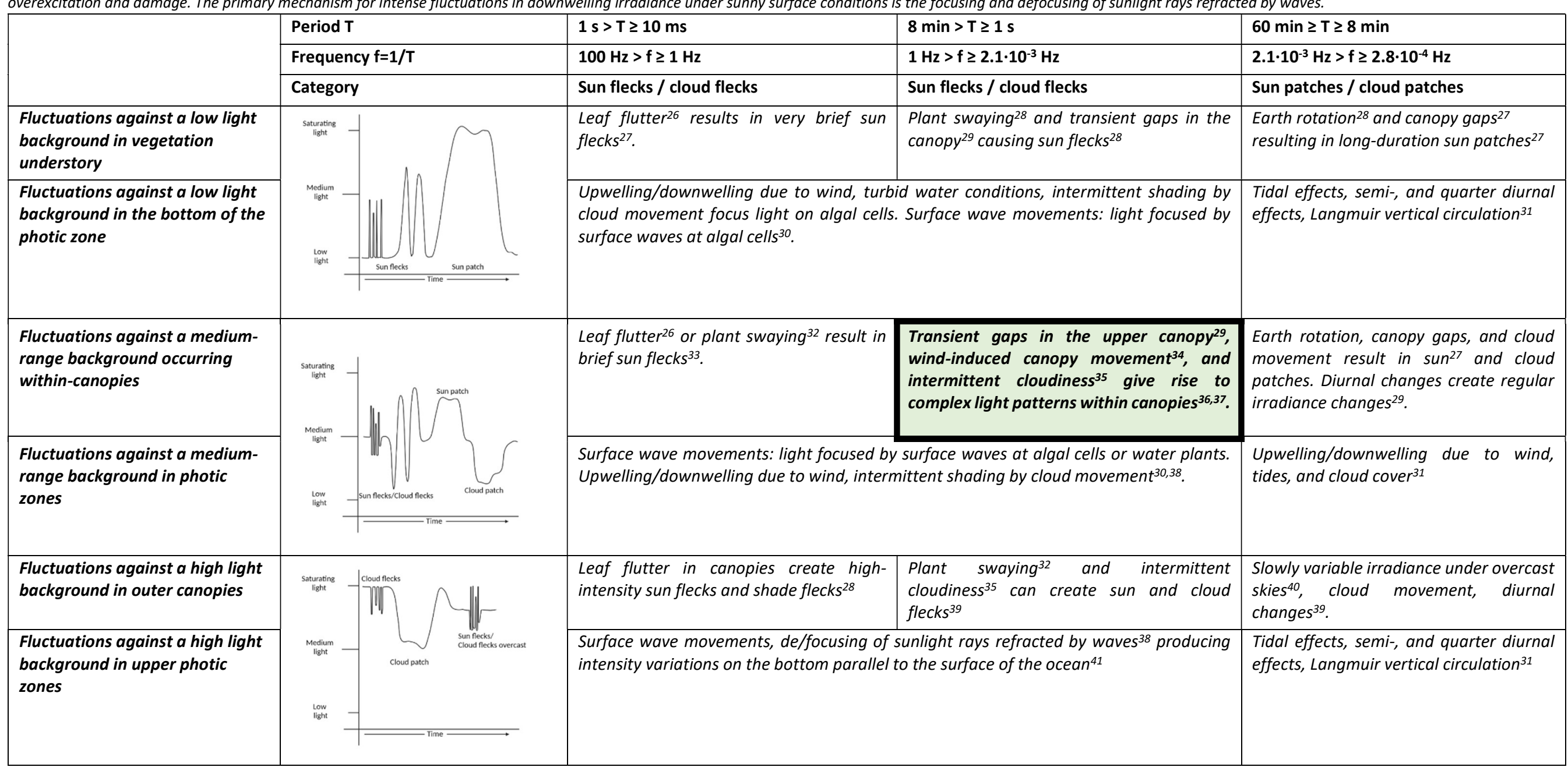

5 | $\mathrm{Niu}$ e t a $\mid$ 


\section{Materials and Methods}

\section{Plant Material and Growth Conditions}

Seeds of Arabidopsis thaliana wild-type Col-0, trichome-lacking wild type Col-gl1, and the mutants affected in NPQ (npq1, npq4) 42,43 and in CET pathways (pgrl1ab, crr2-2) $)^{44-46}$ were sown in commercial soil (Pikier, Balster Einheitserdewerk, Fröndenberg, Germany). Col-0 was the background of the $n p q 1, n p q 4$, and pgrl1ab mutants, and the Col-gl1 was the background of $c r r 2-2$. After 3 days of stratification in a $4^{\circ} \mathrm{C}$ dark room, the seedlings were grown in a climate chamber under the controlled condition: approx. $100 \mu \mathrm{mol}$ photons $\mathrm{m}^{-2}$ $\mathrm{s}^{-1}, 12 \mathrm{~h} / 12 \mathrm{~h}$ light/dark photoperiod, $26^{\circ} \mathrm{C} / 20^{\circ} \mathrm{C}$ day/night air temperature, and $60 \%$ relative air humidity. On the $15^{\text {th }}$ day after the sowing, the seedlings were transferred to pots $(7 \times 7 \times 8 \mathrm{~cm}$, one plant per pot) filled with soil (Lignostrat Dachgarten extensive, HAWITA, Vechta, Germany). The environmental conditions in the climate chamber remained the same as for the seedlings. The plants were watered from the bottom to keep soil moisture throughout the cultivation and during the experiments. All the measurements were performed in the sixth week after sowing.

The wild-type Col-0 plants respond to the acidification of thylakoid lumen in a strong light by down-regulating the flow of excitonic energy to Photosystem II reaction centers by NPQ ${ }^{12,42,47-52}$. This protection against photoinhibition consists of multiple processes that involve protonation of the PsbS protein and the conversion of violaxanthin to zeaxanthin, both schematically represented in Fig.1. The npq1 mutant, lacking the violaxanthin-deepoxidase enzyme (VDE), cannot convert violaxanthin into zeaxanthin ${ }^{43}$, whereas the npq4 mutant lacks the PsbS protein ${ }^{42}$.

The wild-type Col-gl1 plants retain PsbS- and VDE-assisted NPQ as well as cyclic electron transport, CET (Fig.1) that contributes to thylakoid power motive force (pmf) by cycling electrons from the acceptor side of Photosystem I to plastoquinone. As in other angiosperms, A. thaliana plants possess two major CET pathways ${ }^{53}$ : The antimycin-A sensitive pathway ${ }^{54,55}$ is facilitated by the Proton Gradient Regulation 5 (PGR5) and Proton Gradient Regulation-like 1 (PGRL1) proteins ${ }^{4,46,56,57}$ that mediate electron transfer from the reduced ferredoxin ( $\mathrm{Fd}$ ) on the acceptor side of Photosystem I to plastoquinone. The alternative antimycinA insensitive pathway is mediated by NADH dehydrogenase-like complex ${ }^{58}$, which accepts electrons from Fd via NADPH/NADH and also reduces plastoquinone to plastoquinol ${ }^{59}$. The crucial role of the CET is in controlling the ATP/ NADPH production ratio. The protein complex involved in the NDH-like-dependent pathway operates, in addition to increasing the PQ-assisted acidification of the thylakoid lumen, as an energy-coupled proton pump, pumping protons from stroma to thylakoid lumen by coupled electron transfer ${ }^{60-64}$. 


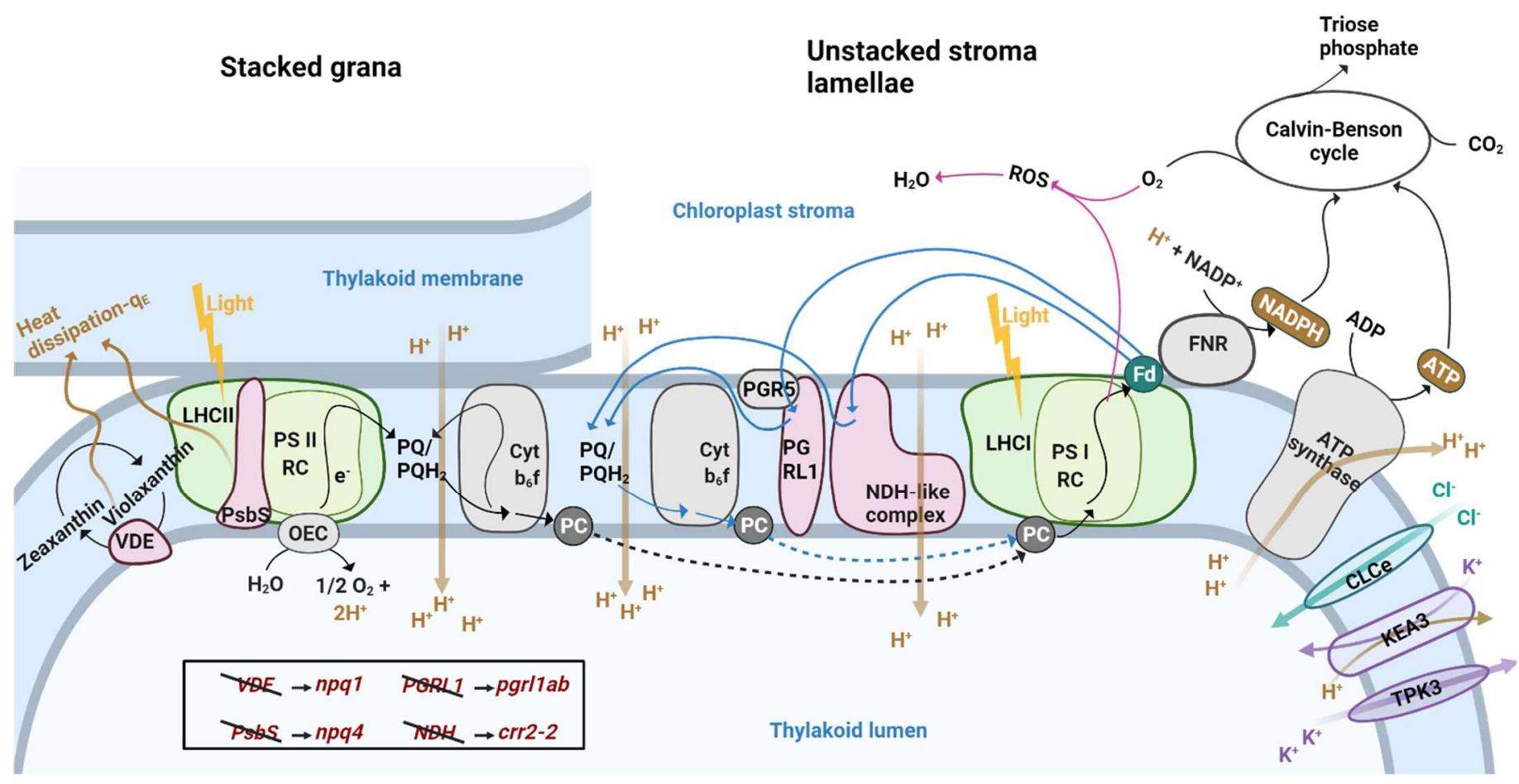

Fig.1. The scheme of the photosynthetic apparatus in A. thaliana and the complexes that are deleted in the npq1, $n p q 4, c r r 2-2$, and prgl1ab mutants. The npq1 and npq4 mutants lack the VDE and PsbS complexes (pink fill), respectively, that are involved in the two coupled mechanisms regulating non-photochemical quenching (qE, NPQ) in Photosystem II. The pgrl1ab and crr2-2 mutants are partially incapacitated in the CTE pathways (blue arrows): prgl1ab lacks PGRL1 complex in the antimycin A-sensitive pathway whereas crr2-2 lacks the NDH-like complex in the antimycin A-insensitive pathway (pink fill). The black arrows indicate the linear electron transport and the downstream Calvin-Benson cycle reactions. The pink arrows show the water-water cycle. The thick brownish arrows indicate the trans-membrane proton transport.

\section{Chlorophyll fluorescence and KLAS-NIR measurements}

In the sixth week after sowing, chlorophyll fluorescence yield and redox changes of PC, P700, and Fd were measured simultaneously using a Dual/KLAS-NIR spectrophotometer with a 3010 DUAL leaf cuvette (Walz, Effeltrich, Germany). Red actinic light (AL, $630 \mathrm{~nm}$ ) was applied from both sides of the leaf. The pulseamplitude-modulated green light $\left(440 \mathrm{~nm}, 6 \mu \mathrm{mol}\right.$ (photons) $\left.\cdot \mathrm{m}^{-2} \cdot \mathrm{s}^{-1}\right)$ was applied from the abaxial side of the leaf to excite chlorophyll.

Differential absorbance of the leaf was measured in the near-infrared part of the spectrum using 780-820, 820-870, 870-965, and 840-965 nm wavelength pairs (NIR-ML). These four respective NIR difference signals were deconvoluted into contributions corresponding dominantly to redox changes of the ferredoxin (Fd), primary donor of PSI (P700), and plastocyanin (PC ${ }^{65,66}$. The deconvolution used the spectra determined by the "Differential Model Plots" (DMPs) routine for redox changes of Fd, P700, and PC 65 . The DMPs were always measured with several replicates of plants, representing separately each genotype of each genotype to check the reproducibility. Typical DMPs were then selected separately for each genotype and used for the respective spectral deconvolution.

Before the experiment and individually for each measured plant, the NIR-MAX routine ${ }^{65}$ was performed to estimate the maximum redox changes of PC, P700, and Fd. Starting with a dark-acclimated plant, a moderate 
$\mathrm{AL}$ of $300 \mu \mathrm{mol}\left(\right.$ photons) $\cdot \mathrm{m}^{-2} \cdot \mathrm{s}^{-1}$ was applied for $3 \mathrm{~s} \mathrm{combined} \mathrm{with} \mathrm{a} \mathrm{saturating} \mathrm{multiple} \mathrm{turnover} \mathrm{light} \mathrm{pulse}$ (MT-pulse) of 100 ms to achieve maximum reduction of Fd. After this, the leaf was exposed to a strong farred light of $740 \mathrm{~nm}$ for $10 \mathrm{~s}$ to largely oxidize PC and P700. Another saturating multiple turnover pulse (100 $\mathrm{ms}$ ) was supplied simultaneously with switching off the far-red light to achieve transient full oxidation of PC and P700 immediately after the MT-pulse ${ }^{65}$.

The deconvolution of the overlapping optical transmission signals in near-infrared and quantitative interpretation ${ }^{65}$ may, to some extent, be compromised by long measuring times during which the initial deconvolution and min-max parameters may drift due to change optical properties of the leaf. This would be of utmost importance in long conventional time-domain measurements that rely on stable reference signals.

With harmonic light forcing, one measures relative changes of the redox states of P700, PC, and Fd that are induced by oscillating light and the method is less sensitive to slowly drifting reference levels. The redox changes are, thus, quantified here relative to the value found when the light oscillation reaches its minimum. In our experiments reported here, the minimum light intensity was always $100 \mu \mathrm{mol}\left(\right.$ photons) $\cdot \mathrm{m}^{-2} \cdot \mathrm{s}^{-1}$. By this, we eliminated potential overinterpretation of the data that were measured over long experimental periods. The dynamic trends occurring during the oscillations were assessed using relative changes of the optical proxies named: apparent relative P700 and PC oxidation, and Fd reduction, respectively.

It is worth noting specific methodological aspects of the Fd signal. The implicit assumption of the NIR-MAX routine is that Fd is fully oxidized in dark. This may not be always correct, because Fd can be reduced by multiple pathways even in dark. This potential caveat may result in an incorrect calibration of the optical proxy and in an apparent drift of the optical signal that is ascribed to fully oxidized Fd. This can, in the end, displace the range of Fd-reduction from the expected range of 0 to $-100 \%$. Therefore, we shall not base any conclusions here on the absolute numerical values of the Fd-redox state but rather focus on trends in the Fd-reduction dynamics relative to the value found at the minimum light intensity $\left(100 \mu \mathrm{mol}(\right.$ photons $) \cdot \mathrm{m}^{-2} \cdot \mathrm{s}^{-}$ $\left.{ }^{1}\right)$.

\section{Actinic light protocols}

The dynamics of photosynthesis and its regulation were studied: (1) in the time-domain by conventional induction following the dark-to-light transition; and (2) in the frequency domain using AL that was oscillating with periods between $1 \mathrm{~s}$ and $8 \mathrm{~min}$. Three intensities of red AL $(630 \mathrm{~nm})$ were used both in time and frequency domains.

\section{Photosynthesis induction measurements}

Each of the dark-adapted plants was first exposed for $10 \mathrm{~min}$ to a constant $\mathrm{AL}$ to record its induction dynamics and acclimate to light before probing the dynamics of forced oscillations. A constant light of 150 $\mu \mathrm{mol}\left(\right.$ photons) $\cdot \mathrm{m}^{-2} \cdot \mathrm{s}^{1}$ was used for the plant that was later exposed to light oscillating between 100 and 200 $\mu \mathrm{mol}\left(\right.$ photons) $\cdot \mathrm{m}^{-2} \cdot \mathrm{s}^{1}$. Induction in $250 \mu \mathrm{mol}$ (photons) $\cdot \mathrm{m}^{-2} \cdot \mathrm{s}^{1}$ was used with plants that were later exposed to oscillations $100-400 \mu \mathrm{mol}\left(\right.$ photons) $\cdot \mathrm{m}^{-2} \cdot \mathrm{s}^{1}$, and induction in $450 \mu \mathrm{mol}$ (photons) $\cdot \mathrm{m}^{-2} \cdot \mathrm{s}^{1}$ was used before oscillations $100-800 \mu \mathrm{mol}\left(\right.$ photons) $\cdot \mathrm{m}^{-2} \cdot \mathrm{s}^{1}$. The saturation pulse (SPs) method was applied to monitor changes in quantum yields of PSII, PSI, and oxidation/reduction of PC and $\mathrm{Fd}^{65}$. The first saturating pulse (630 $\mathrm{nm}$ with approx. $3700 \mu \mathrm{mol}$ (photons) $\cdot \mathrm{m}^{-2} \cdot \mathrm{s}^{1}$ ) was given in the dark to determine the minimum $\left(F_{0}\right)$ and maximum $\left(F_{m}\right)$ chlorophyll fluorescence of PSII. After a 40-s delay, the AL was switched on for the next 10 $\mathrm{min}$. The SPs (630 nm with approx. $17000 \mu \mathrm{mol}\left(\right.$ photons) $\cdot \mathrm{m}^{-2} \cdot \mathrm{s}^{1}$ ) were repeatedly triggered every $30 \mathrm{~s}$. The 
duration of SPs was fixed at $300 \mathrm{~ms}$. An example of the raw induction data is provided in Supplementary Materials Fig.SM-1.

\section{Forced oscillations with changing frequencies and amplitudes}

The photosynthetic induction in the constant AL was, without interruption, followed by $A L$ that was oscillating around the same level. Three different amplitudes of sinusoidal light were applied: 100-800, 100400 , and $100-200 \mu \mathrm{mol}$ (photons) $\cdot \mathrm{m}^{-2} \cdot \mathrm{s}^{1}$, each with a different plant. The frequency (periods) and the number of periods of sinusoidal light were set in the "Trigger Run" window in the KLAS-100 software (Heinz Walz, $\mathrm{GmbH}$, Effeltrich, Germany). The periods were changing in a single continuous sequence: three periods of 8 min, five periods of each $4 \mathrm{~min}, 2 \mathrm{~min}, 1 \mathrm{~min}, 30 \mathrm{~s}$, and $10 \mathrm{~s}$, and ten periods of $5 \mathrm{~s}$ and $1 \mathrm{~s}$. The light was controlled by an 8-bit DA-converter, yielding only 256 light levels to cover the maximum range of the light intensities. The "sinusoidal" light changes were thus occurring in discrete steps rather than smoothly: The oscillations consist approximated of 16 light steps (eight steps increasing, eight steps decreasing) for 100$200 \mu \mathrm{mol}\left(\right.$ photons) $\cdot \mathrm{m}^{-2} \cdot \mathrm{s}^{1}, 44$ light steps for $100-400 \mu \mathrm{mol}$ (photons) $\cdot \mathrm{m}^{-2} \cdot \mathrm{s}^{1}$, and 98 light steps for $100-800$ $\mu \mathrm{mol}\left(\right.$ photons) $\cdot \mathrm{m}^{-2} \cdot \mathrm{s}^{1}$. The experiments were repeated at least three times and at least three biological replicates were used in every treatment.

\section{Analysis of the signals induced by oscillating light}

The first period of 8 mins oscillation was largely influenced by the transition from constant to oscillating light and the first two periods of the other oscillations were influenced by the change of light frequency and, thus, not analyzed. The later periodic signals were already largely stationary and used to extract the respective dynamic features by numeric analysis. The data representing each respective frequency in multiple plants were averaged and statistically analyzed. The signal averages were then numerically approximated by a function Fit $(t)$, consisting of a fundamental mode and of 3 upper harmonic modes as described by Nedbal and Lazar?:

$$
F i t(t)=A_{0}+A_{1} \cdot \sin \left[\mathbf{1} \cdot \frac{2 \pi\left(t-\tau_{1}\right)}{T}\right]+A_{2} \cdot \sin \left[2 \cdot \frac{2 \pi\left(t-\tau_{2}\right)}{T}\right]+A_{3} \cdot \sin \left[\mathbf{3} \cdot \frac{2 \pi\left(t-\tau_{3}\right)}{T}\right]+A_{4} \cdot \sin \left[\mathbf{4} \cdot \frac{2 \pi\left(t-\tau_{4}\right)}{T}\right]
$$

The fitted signals of P700, PC, and Fd apparent redox changes were normalized by dividing by the signals obtained at the minimum light level $\left(100 \mu \mathrm{mol}\right.$ (photons) $\left.\cdot \mathrm{m}^{-2} \cdot \mathrm{s}^{-1}\right)$ as explained above. Each genotype is represented here by at least three biological replicates.

\section{Results}

Dynamic phenomena in light depend on the actinic effects that the irradiance exerts. Photon flux density, wavelength, and angle of incidence relative to the leaf surface can change the photosynthesis rates substantially and it is, thus, important to provide a reference by showing first the commonly measured photosynthesis induction as it occurs with the same experimental geometry after exposing a dark-acclimated plant to the corresponding constant actinic light.

\section{Induction in constant light}

The NPQ mutants and, to some extent, also the CET mutants are expected to be affected in their capacity to respond to strong light in one or more of the multiple components of the non-photochemical quenching ${ }^{50,67}$. The constituent NPQ processes in the $n p q 1$ and $n p q 4$ mutants are affected directly by the deletion of VDE and PsbS, respectively. The CET mutants, pgrl1ab and crr2-2 are affected in the pathways that lead to the reduction of the plastoquinone pool and acidification of the thylakoid lumen, also with the potential of 
affecting NPQ (Fig.1). The induction of NPQ in the respective WT and mutants by 10 min exposure to three different light levels is shown in Fig.2.
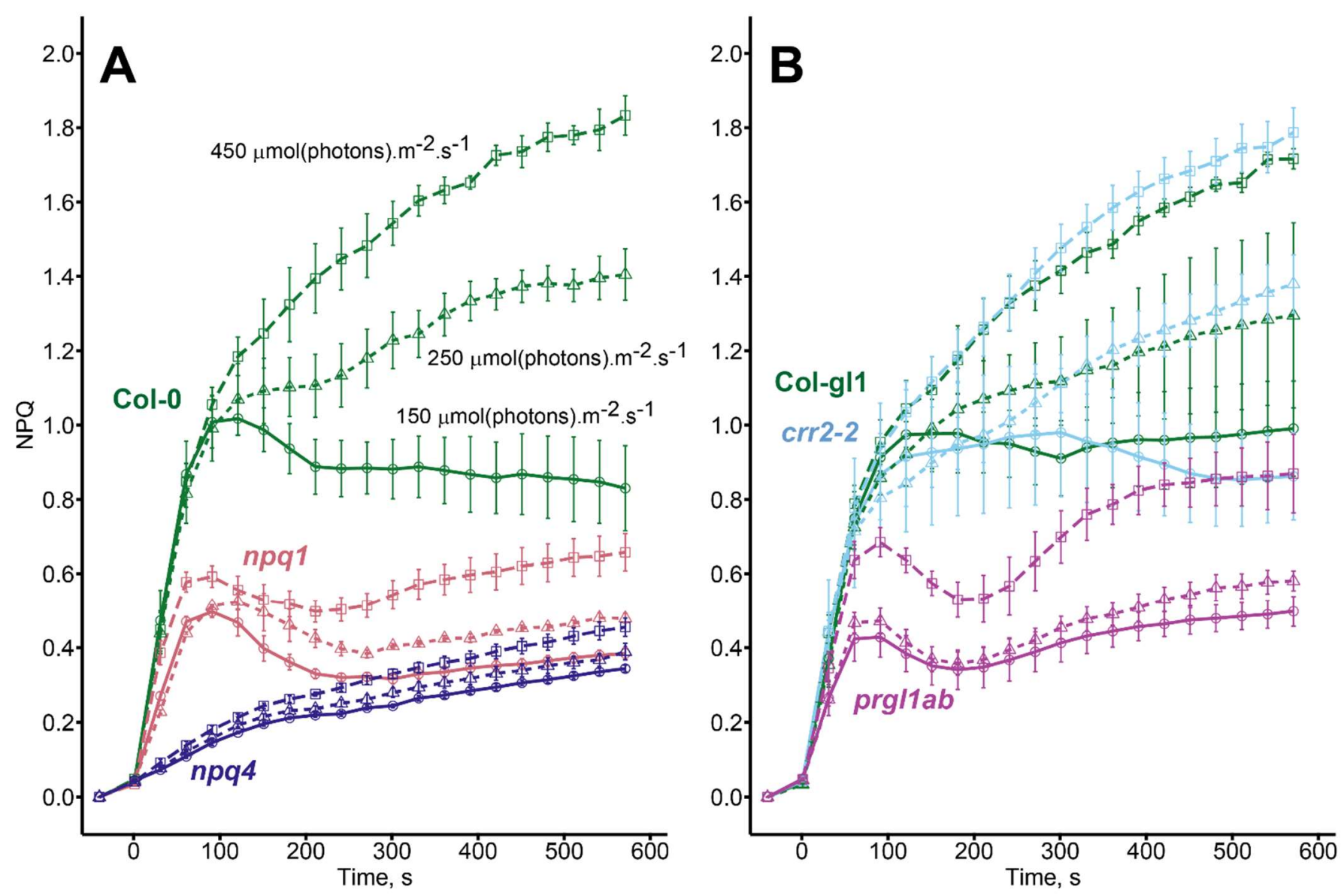

Fig.2 The dynamics of the non-photochemical quenching parameter NPQ in A. thaliana leaves exposed to 150 (circles), 250 (triangles), or 450 (squares) $\mu \mathrm{mol}$ (photons) $\cdot \mathrm{m}^{-2} \cdot \mathrm{s}^{1}$ of constant photosynthetically active irradiance. Panel A compares the wild type Col-0 (green) with the mutants $n p q 1$ (rose) and $n p q 4$ (indigo) that are affected directly by the deletion of VDE and PsbS, respectively. The right panel (B) compares the wild type Col-gl1 (green) with the mutants crr2-2 (light blue) and pgrl1ab (magenta). The time scale marks the time of the AL exposure, with $0 \mathrm{~s}$ being the start of the AL (the first SP in the light was triggered 1s after the AL turning on). The error bars show standard errors $(n=3-9)$ calculated from at least three biological replicates.

The NPQ dynamics after the dark-to-light transition is similar in both wild types, Col-0 (Fig.2A) and Col-gl1 (Fig.2B), always exhibiting two phases: a fast one in the range of tens of seconds after the light was switched on and a slow one dominating on the scale of several minutes thereafter. Also, the NPQ amplitudes are similar in both wild-type genotypes showing that the ratio between the rate constant of the light-induced, regulatory quenching and the constituent non-regulatory quenching was about the same in both WT genotypes. The amplitude and kinetics of the NPQ induction in the fast phase were about the same, regardless if 150,250 , or $450 \mu \mathrm{mol}\left(\right.$ photons) $\cdot \mathrm{m}^{-2} \cdot \mathrm{s}^{1}$ of constant photosynthetically active irradiance was applied. The second, slower phase was, in contrast, strongly light-dependent, effectively occurring only in the highest irradiance of $450 \mu \mathrm{mol}\left(\right.$ photons) $\cdot \mathrm{m}^{-2} \cdot \mathrm{s}^{1}$. The observed kinetics correspond to earlier reports $^{9,42,48,68,69}$ in the sense that the response of the $n p q 4$ (PsbS-deficient) mutant lacked the fast phase that dominated under our experimental conditions ca. the first 90s in the Col-0 WT and was, to a lower extent, also observed with the npq1 (zeaxanthin-deficient) mutant. The slower phase of the NPQ increase 
dynamics appeared in the WT only in high light whereas it was absent or even decreasing in low light. This NPQ decline appearing after the transient maximum at ca. 90 seconds was also seen in the npq1 mutant.

The crr2-2 mutant that is defective in the NDH-like pathway of CET exhibited an NPQ-dynamics that was qualitatively similar to the wild type. This is in agreement with previous studies reporting similar chlorophyll fluorescence quenching for the wild type and the NDH-like mutant ${ }^{22,44}$. The pgrl1ab mutant that lacks the PGR5-PGRL1 pathway of CET exhibited contrasting NPQ dynamics, supporting the notion that the latter pathway plays in CET a substantial role ${ }^{18,45,70,71}$. Notably, the observed induction of NPQ in the pgrl1ab mutant resembled the NPQ dynamics of the npq1 mutant that lacks violaxanthin deepoxidase (VDE). The course of NPQ of the pgrl1ab mutant agrees with previously published results with pgrl1 mutants ${ }^{72}$. Hence, the threshold lumen acidification required for initiating the PsbS-dependent NPQ can be generated solely with LET. The additional lumen acidification contributed by PGRL-mediated CET may be required to initiate also the VDE-dependent NPQ that is not available in the pgrl1ab mutant. This hypothesis is consistent with the pKa values that are 6.0 for VDE- and 6.4 for $\mathrm{PsbS}^{73,74}$.

The constant-light experiment in Fig. 2 served also to define the initial condition for the immediately following experiment, in which the light was oscillating. The late phase of the induction kinetics in Fig.2 documented the convergence of NPQ to the light-acclimated levels. Similarly, the apparent redox states of PC, P700, and Fd also converged close to their steady-state levels of light acclimation (Supplementary materials Fig.SM-2 \& Fig.SM-3, Supplementary materials Table.SM-1), around which the oscillations in the second phase of the experiment occurred.

\section{Photosynthetic dynamics in light oscillating with periods of $30 \mathrm{~s}$ and $4 \mathrm{~min}$.}

The induction experiment in constant light (Fig.2) showed that the NPQ regulation appeared, under our conditions, in two phases: one with a time constant of tens of seconds and the slower one taking several minutes, in agreement with earlier studies ${ }^{50,75}$. Based on this, it can be expected that also the response to light oscillating with a period of tens of seconds will be different from that oscillating with a period of several minutes. Dynamics of the Chl-F yield, the apparent relative PC and P700 oxidation, and apparent relative Fd reduction in Col-0 WT, npq1, and npq4 A. thaliana plants are shown in Fig.3 for light oscillating between 100 and $400 \mu \mathrm{mol}\left(\right.$ photons) $\cdot \mathrm{m}^{-2} \cdot \mathrm{s}^{-1}$ with the periods of 30 seconds and 4 minutes. 
bioRxiv preprint doi: https://doi.org/10.1101/2022.02.09.479783; this version posted February 10, 2022. The copyright holder for this preprint (which was not certified by peer review) is the author/funder. All rights reserved. No reuse allowed without permission.
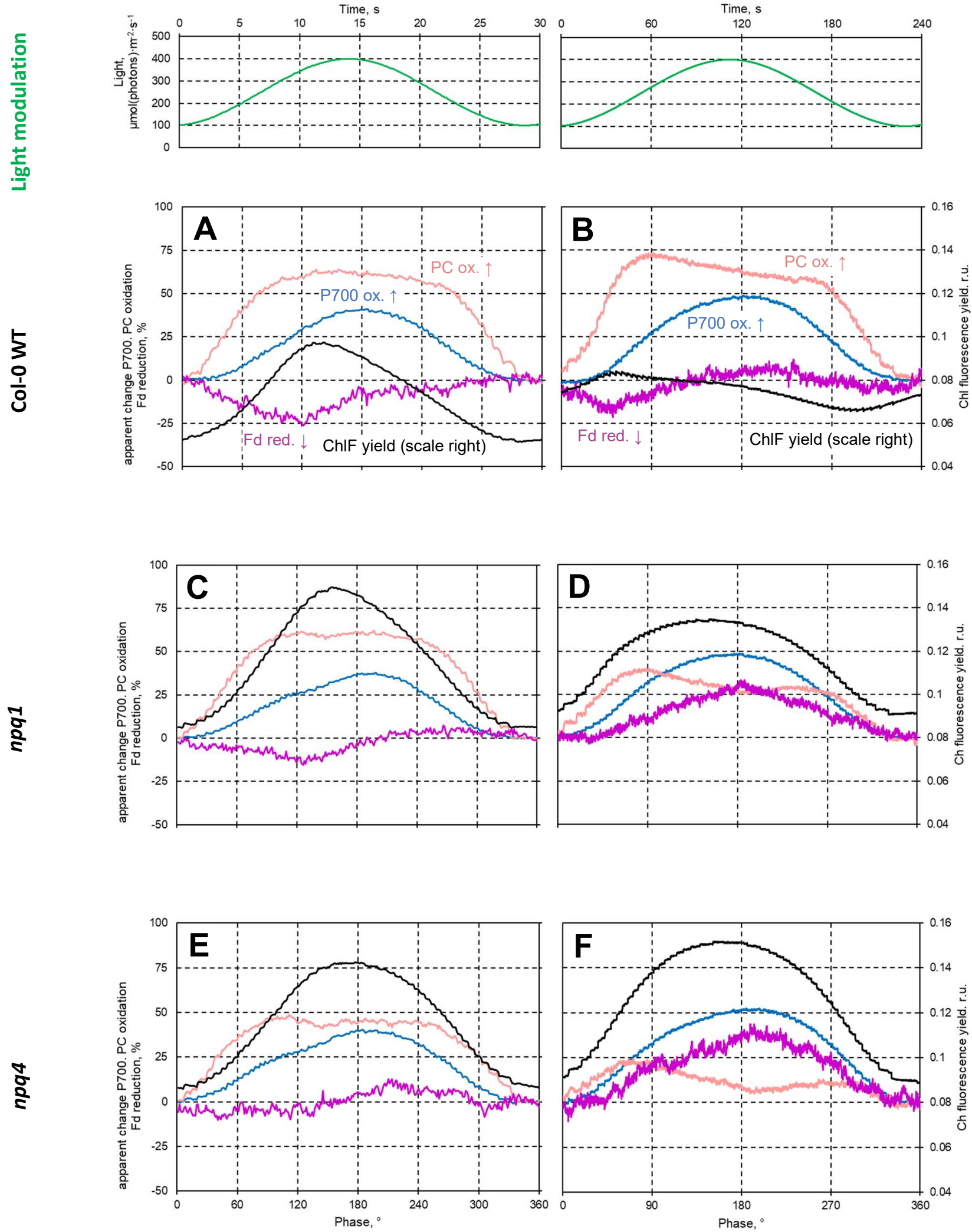

Fig.3. Dynamics of the Chl-F yield (black, the right Y-axis), the apparent relative PC (pink) and P700 oxidation (blue), and Fd reduction (magenta) in A. thaliana wild type Col-0, in npq1 and npq4 mutants exposed to oscillating light (green, top row). The Chl-F yield values depend on the PAM instrument sensitivity, with the scale defined by the $F_{m}$ values being $0.278 \pm 0.003$ in Col-0 WT, $0.277 \pm 0.005$ in $n p q 1$, and $0.272 \pm 0.005$ in npq4. The light was oscillating between 100 and $400 \mu \mathrm{mol}$ (photons) $\cdot \mathrm{m}^{-2} \cdot \mathrm{s}^{-1}$ with the periods of 30 seconds (left column) and of 4 minutes (right column). 
The amplitude of the oscillatory-light-driven variations in Chl-F was found to be strongly reduced by the nonphotochemical quenching (NPQ) in the wild-types Col-0 (Fig.3A, B) and Col-gl1 (Fig.4A, B) genotypes, both with NPQ and CET fully functional. The reduction of the NPQ variation amplitudes was particularly strong in the slow oscillations with $\mathrm{T}=4 \mathrm{~min}$ (Fig.3B). In the fast oscillations with $\mathrm{T}=30 \mathrm{~s}$ (Fig. $3 \mathrm{~A}$ ), the damping was less effective, presumably, because the NPQ-regulation could not follow the rapid changes in the illumination fast enough. In the $4 \mathrm{~min}$-oscillations, Chl-F yield first rose slightly with light that increased from the minimum at $100 \mu \mathrm{mol}$ (photons) $\cdot \mathrm{m}^{-2} \cdot \mathrm{s}^{-1}$ (phase $0^{\circ}$ ) to $200 \mu \mathrm{mol}$ (photons) $\cdot \mathrm{m}^{-2} \cdot \mathrm{s}^{-1}$ (phase $60^{\circ}$ ), approx. $40 \mathrm{~s}$ after the initial light minimum. It was likely due to an onset of the fast PsbS-dependent NPQ that prevented further Chl-F yield increase beyond this local maximum. Simultaneously with the Chl-F yield maximum, the maximal reduction of Fd occurred ${ }^{a}$, while, for PC, this was approximately an inflection point beyond which the PC oxidation did not accelerate further and reached its maximum one minute after the light started rising from its minimum to ca. $275 \mu \mathrm{mol}$ (photons) $\cdot \mathrm{m}^{-2} \cdot \mathrm{s}^{-1}$ at $90^{\circ}$ phase. The light was reaching its maximum after around 2 minutes, $180^{\circ}$ phase shift after the initial minimum ${ }^{b}$. The maximum P700 oxidation occurred close after the light maximum whereas the PC oxidation was in a shallow saddle depression and Fd was partially oxidized.

The decrease of $\mathrm{ChI}-\mathrm{F}$ yield then continued until ca. $300^{\circ}$ when the actinic light was already strongly dimmed back to $150 \mu \mathrm{mol}$ (photons) $\cdot \mathrm{m}^{-2} \cdot \mathrm{s}^{-1}$ and the Chl-F yield reached its minimum coinciding with a rapid drop of PC oxidation and another increase in the Fd reduction. The last phase of light decreasing from 150 to 100 $\mu \mathrm{mol}\left(\right.$ photons) $\cdot \mathrm{m}^{-2} \cdot \mathrm{s}^{-1}\left(300^{\circ}\right.$ to $\left.360^{\circ}\right)$ was marked by Chl-F yield recovering from the NPQ.

The light applied in the experiments in Fig. 3 was relatively moderate and one can understand the dynamics dictated in WT plants by moderate NPQ quenching. With the linear electron transport from Photosystem II reduced by NPQ that is, particularly in slow oscillations, not outpowered by too strong or rapid light changes, one can expect that the dynamics of PC, P700, and Fd is reflecting primarily CET. In the moderate light intensities, Fd reoxidation towards NADPH is very effective and, thus, the Fd remains largely stable and oxidized in WT. The cyclic flow of electrons from Fd back to PC and P700 may culminate with a delay after the initial "wave" going primarily towards NADPH. The first preferential reduction of NADPH leaves fewer electrons for $\mathrm{CET}$, increasing the fraction of $\mathrm{PC}^{+}$and $\mathrm{P} 700^{+}$around the light maxima in WT. This qualitative hypothesis needs to be further tested by additional experiments that will be confronting quantitative dynamic models.

The dynamic of the Chl-F yield in the npq1 (zeaxanthin deficient) mutant in the 30s-period oscillations (Fig.3C) was like that observed in WT Col-0 presumably because the zeaxanthin (VDE)-related NPQ cannot follow the rapid light oscillation while the PsbS-related NPQ was the same in both organisms ${ }^{75,77,78}$. In the light oscillating with the long period of 4 minutes (Fig.3D), however, the Chl-F yield varied much more in the zeaxanthin-deficient npq1 mutant than in the wild type, confirming the role of the xanthophyll cycle in the WT in the slow oscillations.

\footnotetext{
${ }^{a}$ In respect to $\mathrm{Fd}$, it is worth noting that when the charge separation induced by light occurs in the PSI core complex, electron transfer from $\mathrm{P} 700$ to $\mathrm{Fd}$ occurs in a series of rapid redox reactions through $\mathrm{AO}$ (the monomeric form of $\mathrm{Chl} a$ ) and $\mathrm{A} 1$ (phylloquinone) to the $[4 \mathrm{Fe}-4 \mathrm{~S}]$ clusters (FX, FA, and FB), and ultimately to $\mathrm{Fd}[2 \mathrm{Fe}-2 \mathrm{~S}]^{65}$. In the case of in vivo measurements, distinguishing the absorption changes of Fd from that of the other FeS proteins is practically impossible, as the NIR differential spectrum of FA-FB is similar to that of the $\mathrm{Fd}^{76}$, and much larger absorption changes caused by other components can influence the signal deconvolution of different FeS proteins ${ }^{65}$. Therefore, the "Fd" signal used in this study is a mixture of signals of FeS components at the PSI acceptor side.

${ }^{b}$ The light modulation was defined in the instrument protocol on the $0-360^{\circ}$ scale with the maximum exactly in the middle of the period at $180^{\circ}$. The actual light modulation produced and measured by the instrument was slightly phase shifted.
} 
bioRxiv preprint doi: https://doi.org/10.1101/2022.02.09.479783; this version posted February 10, 2022. The copyright holder for this preprint (which was not certified by peer review) is the author/funder. All rights reserved. No reuse allowed without permission.
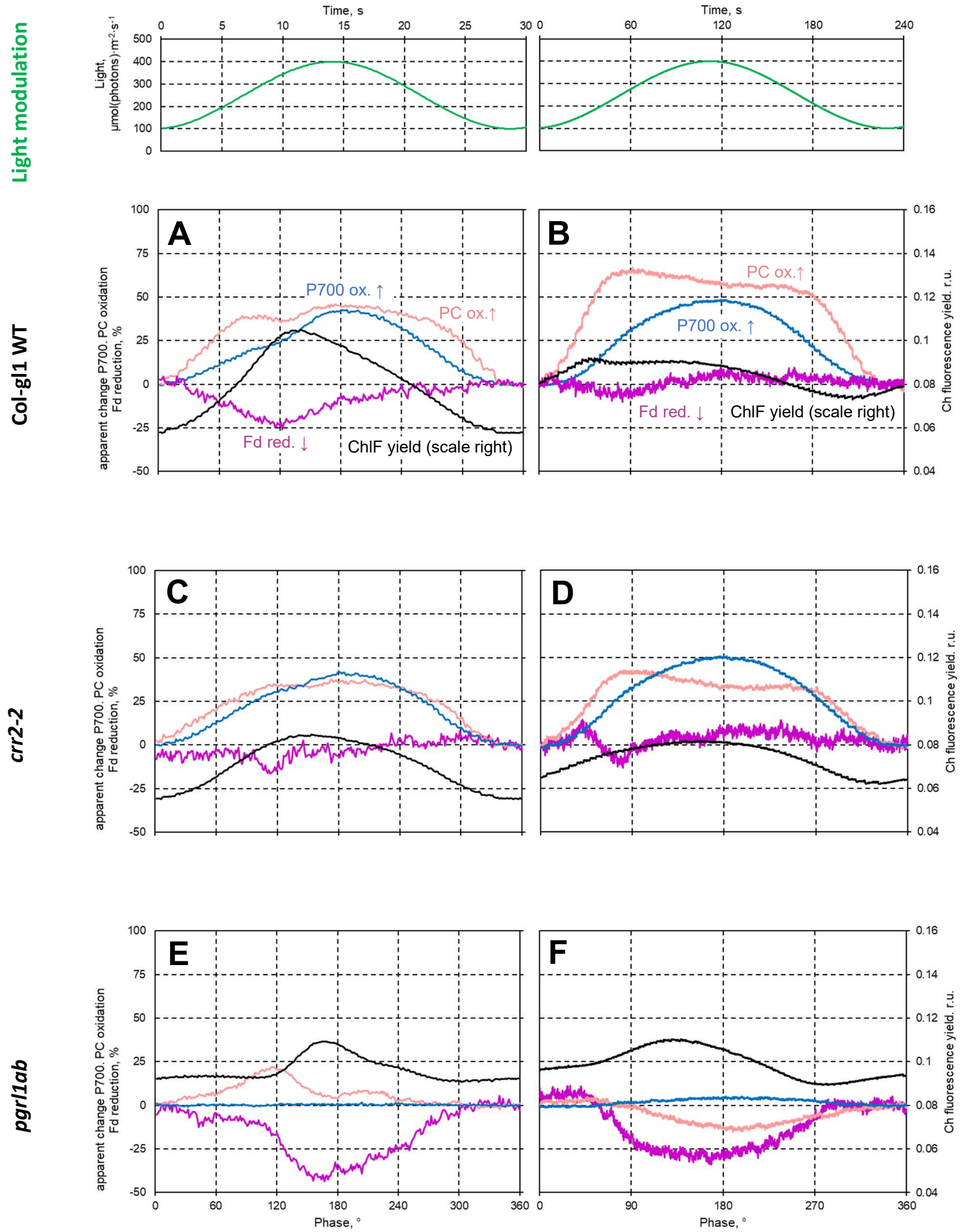

Fig.4. Dynamics of Chl-F yield (black, the right axis), of PC (pink) and P700 oxidation (blue), and Fd reduction (magenta) in A. thaliana wild type Col-gl1, in crr2-2 and pgrl1ab mutants exposed to oscillating light (green, top row). The Chl-F yield values depend on the PAM instrument sensitivity, with the scale defined by the $F_{m}$ values being $0.281 \pm 0.006$ in Col-gl1 WT, $0.265 \pm 0.005$ in crr2-2, and $0.268 \pm 0.005$ in prgllab. The light was oscillating between 100 and $400 \mu \mathrm{mol}$ (photons) $\cdot \mathrm{m}^{-2} \cdot \mathrm{s}^{-1}$ with the periods of 30 seconds (left column) and of 4 minutes (right column). 
The Chl-F yield in the npq4 (PsbS-deficient) varied with a large amplitude (Fig.3E, F), approximately following the oscillating time course regardless of the light oscillation period. This indicates that npq4 had no effective regulation to respond to oscillating light of the $30 \mathrm{~s}$ and 4 min periods.

Interestingly, the apparent relative Fd signal indicated oxidation with increasing light in both npq1 and npq4 when the oscillations were slow (Fig.3D, F). The maximum apparent relative Fd oxidation was measured soon after the light oscillated to its maximum, coinciding with the local relative apparent re-reduction of PC in the topological saddle.

The photosynthetic dynamics induced by $30 \mathrm{~s}$ oscillating light in WT Col-gl1 (Fig.4A) was like the WT Col-0 (Fig.3A) only a dip in the P700 and PC oxidation that coincided at the $10^{\text {th }}$ second with the maxima in the $\mathrm{Fd}$ reduction and Chl-F yield appeared in Col-gl1. However, this dynamic feature was sometimes found in a pronounced form also in Col-0. The variability in the dynamic features is documented in detail in Supplementary Materials (from Fig.SM-4.1 to 6). The dynamics found with the oscillation period of 4 minutes (Fig.4B, 3B) and effective NPQ were very similar in both WT genotypes.

The photosynthetic inductions in constant light in the crr2-2 mutant were not much different from WT (Fig.2). This further supports the earlier conclusion that the deletion of the NDH-like gene does not alter photosynthesis in constant light significantly ${ }^{44}$. The Chl-F yield transients found in crr2-2 and WT in oscillating light were however somewhat different, c.f. black lines in Fig.4C, D with Fig.4A, B and Fig.3A, B. This difference was well seen in the 4 min oscillations when the crr2-2 Chl-F dynamics resembled the one in npq1 (c.f. Fig.4D with Fig.3D). This finding agrees with the previous study on the structure and function of the $\mathrm{NDH}$-like complex in chloroplasts ${ }^{79}$ which, in the WT, pumps electrons into the thylakoid lumen and contributes thus to NPQ.

In contrast to the relatively minor modification of the photosynthesis dynamics in crr2-2, the pgrl1ab mutation lead to a strong modification compared to the wild-type genotype (c.f. Fig.4E, F with Fig.4A, B and Fig.3A, B). With this major CET pathway incapacitated by the mutation, the dynamics were primarily driven by the linear electron transport from water to $\mathrm{CO}_{2}$ or other $\mathrm{Fd}$-oxidizing pathways. In the slowly oscillating light ( $4 \mathrm{~min}$ in Fig.4F), the most prominent redox change was the reduction of $\mathrm{Fd}$ that was driven in this mutant dominantly by the linear electron transport and which culminated before the light oscillation maximum ( $\approx 2 \mathrm{~min}, 180^{\circ}$ in Fig.4 top right). The reduction of the Fd-associated proxy (see footnote ${ }^{\mathrm{a}}$ above) cannot alleviated be in this mutant by CET and is much stronger than in the WT. The Fd proxy is reduced by ca. $25-30 \%$ more in $400 \mu \mathrm{mol}$ (photons) $\cdot \mathrm{m}^{-2} \cdot \mathrm{s}^{-1}$ of the oscillation maximum compared to the refence level attained in $100 \mu \mathrm{mol}\left(\right.$ photons) $\cdot \mathrm{m}^{-2} \cdot \mathrm{s}^{-1}$ of the oscillation minimum. The resulting limitation of the electron transport on the acceptor side of PSI caused probably also the slight reduction of PC in $400 \mu \mathrm{mol}$ (photons) $\cdot \mathrm{m}^{-}$ $2 \cdot \mathrm{s}^{-1}$ relative to $100 \mu \mathrm{mol}\left(\right.$ photons) $\cdot \mathrm{m}^{-2} \cdot \mathrm{s}^{-1}$. P700 redox was hardly changing, presumably, because its reduction and oxidation were, without the major CET pathway, balanced. Mingzhu Ma et al. ${ }^{80}$ noted that the PSI remains fully reduced under high light in the pgr5 mutant and our data suggest that this may remain valid even when the light oscillates.

In the pgrl1ab mutant, the Chl-F yield during the light oscillation was first not much influenced by the increasing light as long as Fd remained in the low light oxidized. The steep reduction of Fd around 1 min after the light minimum ( $90^{\circ}$ in Fig.4F) was soon thereafter followed by the rise in the Chl-F yield that signaled reduction of the plastoquinone pool and an ensuing reduction of the photochemical quenching. The reduction of the plastoquinone pool was propagated to a delayed reduction of PC. The maximum of Chl-F yield was reached at about $145^{\circ}$ phase (Fig.4F) and was followed by a decline that occurred despite the light that continued increasing further to ca. $180^{\circ}$ phase (Fig.4 top right). This Chl-F yield decline can be tentatively 
bioRxiv preprint doi: https://doi.org/10.1101/2022.02.09.479783; this version posted February 10, 2022. The copyright holder for this preprint (which was not certified by peer review) is the author/funder. All rights reserved. No reuse allowed without permission.

attributed to the onset of NPQ that eventually also eliminated the Fd reduction that was limiting the linear ET until ca. $270^{\circ}$ phase (Fig.4F).

In comparison to the 4 min period discussed above, pgrl1ab mutant exhibited much sharper dynamic features, with strong upper harmonic modulation when exposed to the rapid $30 \mathrm{~s}$ oscillation (Fig.4E). This was caused, probably, by a dynamic load disharmony of rapid 'push-pull effects' of reduction by PSII and oxidation by PSI in the linear ET. The first apparent feature at the ca. $120^{\circ}$ phase was the transient oxidation of PC (Fig.4E). That was soon thereafter followed by a sharp rise of the Chl-F yield that signaled plastoquinone pool reduction which coincided with a rapid re-reduction of $P C$ and reduction of Fd, all at ca $160^{\circ}$ (Fig.4E). Soon thereafter the light ceased increasing and NPQ became activated, both leading to a gradual drop in Chl-F yield, and in Fd re-oxidation.

The results in Figs. 3 and 4 reveal an interesting dynamic disharmony between the apparent changes of P700 and PC oxidation. Figs. 3 and 4, particularly the data for $\mathrm{T}=4 \mathrm{~min}$ show dynamics of P700 and PC oxidation that were very different from each other. With small deviations, the P700 oxidation approximately follows the dynamics of the oscillating light, with more oxidation in stronger light (details of apparent change in P700 in the light oscillating between 100 and $800 \mu \mathrm{mol}$ (photons) $\cdot \mathrm{m}^{-2} \cdot \mathrm{s}^{-1}$ are documented in Supplementary Materials Fig.SM-5). In contrast, the PC oxidation dynamics often exhibit a local depression around the light maximum, forming a pronounced topological saddle. This phenomenon is most evident in the oscillation of the largest amplitude $\left(100-800 \mu \mathrm{mol}(\right.$ photons $\left.) \cdot \mathrm{m}^{-2} \cdot \mathrm{s}^{-1}\right)$. This is further shown in the comparison of the dynamics P700 and PC in different intensities of oscillation in Supplementary Materials Fig.SM-6.2 and 3. With PC being the direct donor of electrons to P700, an increasing fraction of oxidized P700 in increasing light may be expected to entail proportional oxidation of PC which is not the case. The ratio between the redox of $\mathrm{PC}$ and $\mathrm{P} 700$ is, thus, influenced by a factor that is changing in the range of minutes. With the trends in the PC dynamics changing at the oscillation phase with ChI-F extremes, we tentatively propose that the PC dynamics, unlike P700 dynamics is modulated by a factor that connects both photosystems, such as photosynthesis control ${ }^{57,81}$ and/or systemic properties such as thylakoid topology ${ }^{82,83}$ that may influence the diffusion of PC.

\section{Frequency-domain analysis of photosynthetic dynamics in oscillating light.}

Dynamics of photosynthesis in oscillating light can identify characteristic time parameters of NPQ and CET if done with many different oscillation periods. Chl-F yield dynamics induced in 6 genotypes of $A$. thaliana by oscillating light with eight periods ranging from $1 \mathrm{~s}$ to $8 \mathrm{~min}$ is shown in Fig.5. The data in Fig.5 show in more detail two extreme dynamic signatures, that were seen already in Figs.3 and 4:

The Chl-F yield in the npq4 mutant follows approximately the oscillating light of all tested periods between $1 \mathrm{~s}$ and $8 \mathrm{~min}$. Due to the absence of PsbS, the rapid qE NPQ form is diminished, and the yield is modulated dominantly by photochemical quenching that is high in low light and low in high light during the oscillation. On the other extreme are both WT genotypes Col-0 and Col-gl1 in which both, the PsbS- and VDE-dependent NPQ mechanisms regulate the photosynthetic activity modulating the Chl-F in oscillating light in a complex manner that is best visible in another graphical format, here shown in Fig.6. The Chl-F yield modulation in the WT genotypes Col- 0 and Col-gl1 is marked by a maximum spreading over the oscillation periods $30 \mathrm{~s}$ and $1 \mathrm{~min}$, respectively (yellow and blue circles). Detailed analysis in Supplementary Materials Fig.SM-7 shows that the maximum shoulder in the $30 \mathrm{~s}$ oscillation period (the yellow circles in Fig.6) originates from the fundamental harmonic that has the same period as the light oscillation. This is a typical feature of a resonance between the forcing frequency and the internal frequency of the investigated system. 
bioRxiv preprint doi: https://doi.org/10.1101/2022.02.09.479783; this version posted February 10, 2022. The copyright holder for this preprint (which was not certified by peer review) is the author/funder. All rights reserved. No reuse allowed without permission.

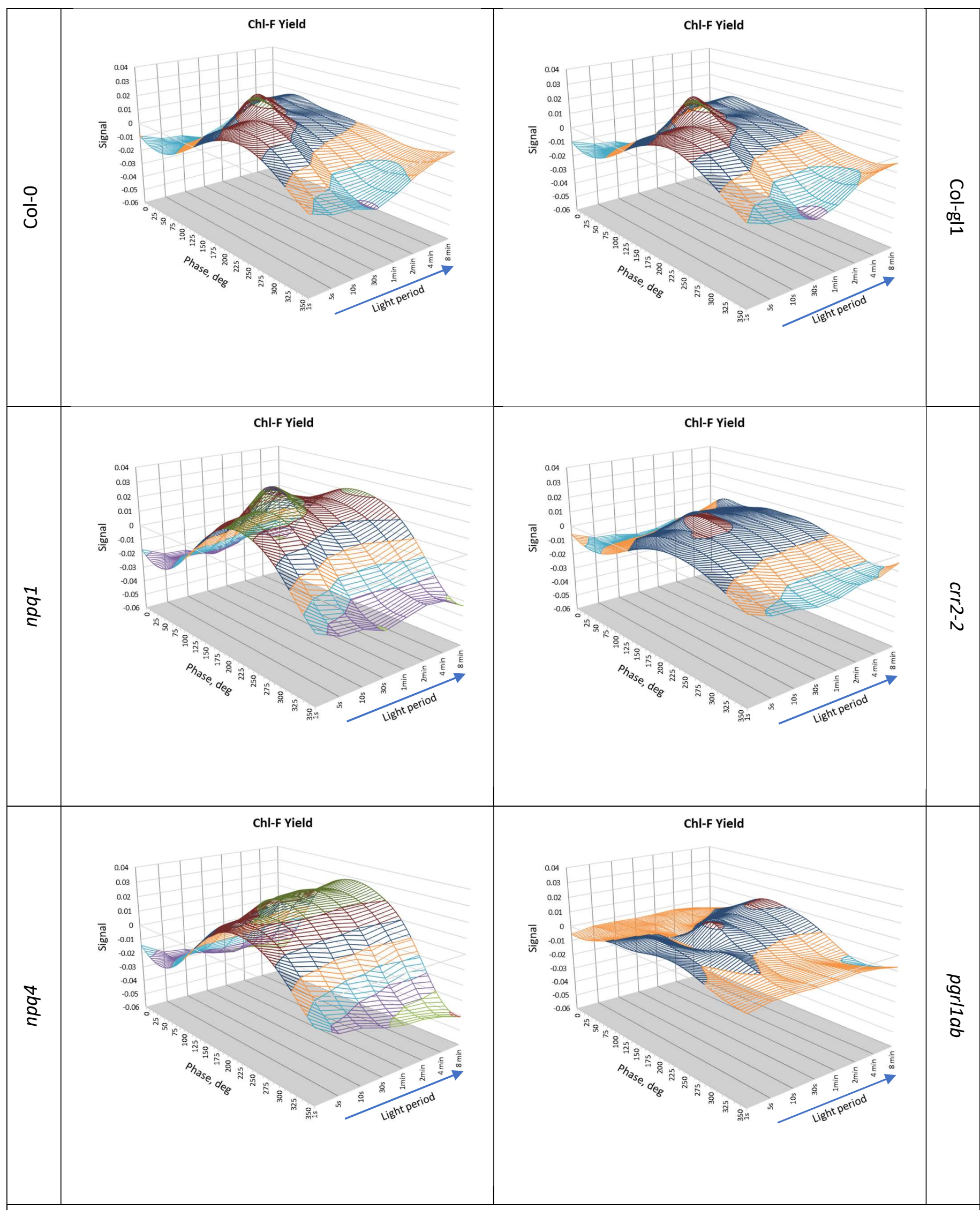

Fig.5. The time-variable part of the Chl-F yield induced in 6 genotypes of $A$. thaliana by light oscillating between 100 and $400 \mu \mathrm{mol}$ (photons) $\cdot \mathrm{m}^{-2} \cdot \mathrm{s}^{-1}$ with the periods in the range $1 \mathrm{~s}$ to $8 \mathrm{~min}$. 
bioRxiv preprint doi: https://doi.org/10.1101/2022.02.09.479783; this version posted February 10, 2022. The copyright holder for this preprint (which was not certified by peer review) is the author/funder. All rights reserved. No reuse allowed without permission.

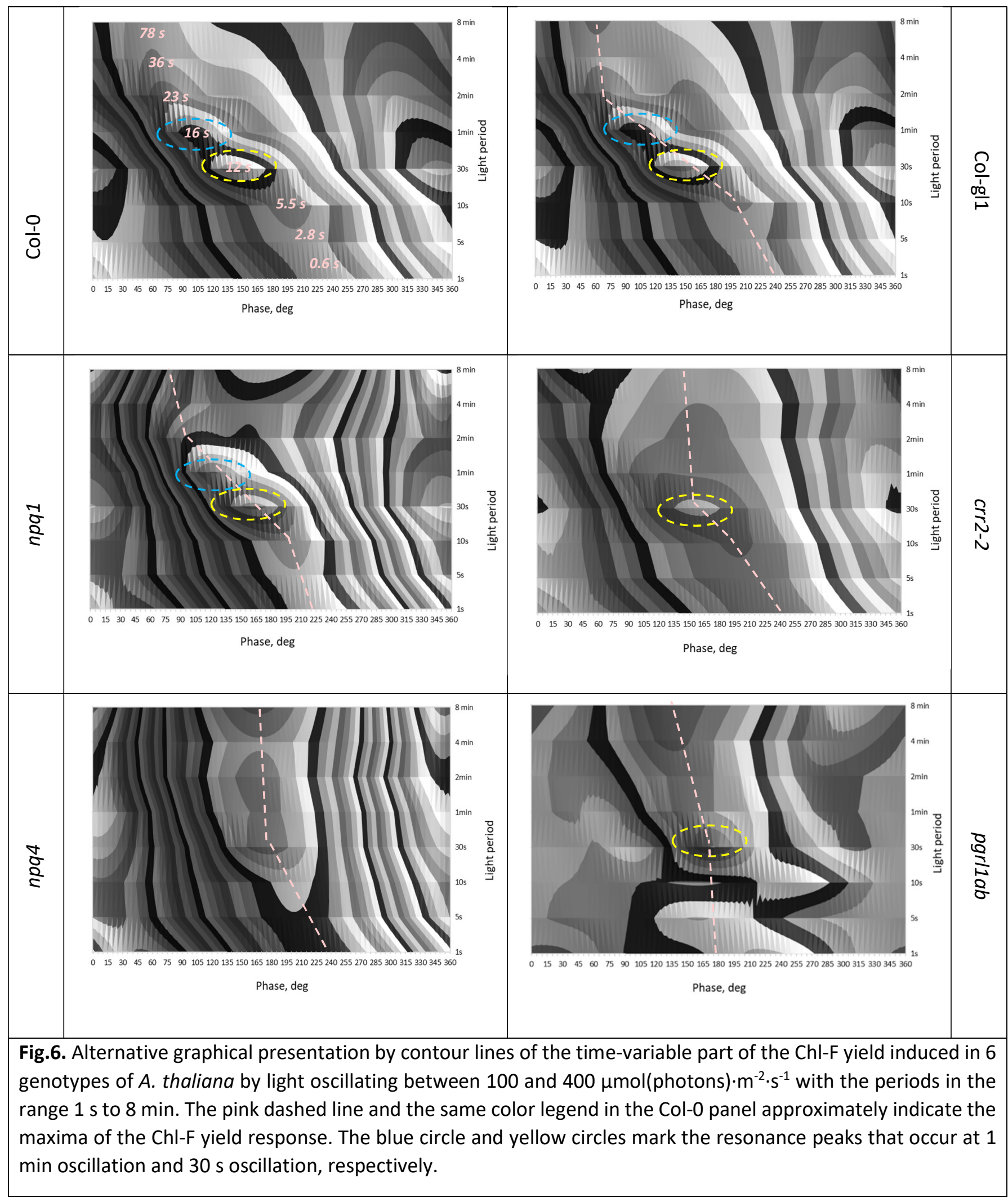


The smaller maximum shoulder Chl-F yield visible with the oscillation period of $1 \mathrm{~min}$ (the blue circles in Fig.6) can be attributed to the upper harmonic components, particularly to the first upper harmonics with $\mathrm{T} / 2$ (Supplementary Materials Fig.SM-7). The upper harmonics were proposed to be an indicator of a nonlinearity caused by a regulation ${ }^{6,7,84}$. The period of 1 minute is also observed in the spontaneous oscillations in plants ${ }^{85,86}$, providing further strong, independent support for the interpretation that the dynamic phenomena observed in the WT with the forcing frequencies $1 / 30$ to $1 / 60 \mathrm{~Hz}$ are due to a resonance between the oscillating light and the internal photosynthetic regulation.

The absence of the $30-60 \mathrm{~s}$ Chl-F maxima in the $n p q 4$ response to oscillating light (Fig.6) is important experimental evidence showing that the regulation responsible for the respective resonance maxima is related to the NPQ regulation, a claim that was earlier based only on predictions by mathematical models $s^{6,7,84}$. This feature suggests the rate constant $1 / 60 \mathrm{~s}^{-1}$ as a dynamic threshold for NPQ regulation in light-acclimated plants. It is important to note that the longer onset of the fast component in the NPQ dynamics in Fig. 2 is not necessarily contradicting this proposal. The rate constants effective during the darkto-light transition (Fig.2) may not necessarily be the same as in the light-acclimated plants (Fig.6).

Further, the dynamic patterns in the apparent relative PC oxidation dynamics that were shown with two local maxima and a saddle depression in between in Figs. 3 and 4 and discussed above are documented with more detail in Fig. $7^{c}$. The saddle feature is deeper in stronger light and, thus, Fig.7 shows data for light oscillating between 100 and $800 \mu \mathrm{mol}$ (photons) $\cdot \mathrm{m}^{-2} \cdot \mathrm{s}^{-1}$. This dynamic feature is not developed for oscillation periods $\leq 30 \mathrm{~s}$ but is fully developed for periods lasting several minutes. In contrast, P700 relative oxidation dynamics (Supplementary Materials Fig.SM-6.4) was always lacking this feature and roughly followed the oscillating light dynamics. Considering that PC was proposed to be responsible for long-distance transfer between cyt $b_{6} f$ and PSI along the thylakoid membrane, one may expect that the putative light-induced reorganization of the membrane ${ }^{82,83}$ might be causing changes in the dynamical equilibrium between $P C$ and P700 oxidation states. This in turn, can be accounting for the different dynamics of PC and P700 (Figs.3 and 4). Notably, the contrast between the P700 and PC dynamics disappears in low light (Supplementary Materials from Fig.SM-9.1 to Fig.SM-9.4) in which PC follows, like P700 the simple dynamics of the light modulation.

Considering the different orientations of the period axis in Figs.7 and 8 (red vs. blue arrow), one can see again two distinct dynamic behaviors in the domain of periods that are shorter than $30 \mathrm{~s}$ and those that are longer than $1 \mathrm{~min}$. All the investigated genotypes except the pgrl1ab mutant, exhibit qualitatively similar behavior with relatively dull and shallow response in the fast oscillations (30 $\mathrm{s}>\mathrm{T}$ ) and with a Fd oxidation and the saddle depression of PC in stronger light levels around the mid-period in the slow oscillations ( $T>1$ $\mathrm{min})$. The PC and Fd signal variability in the pgrl1ab mutant are apparently lower than in the other genotypes further supporting the strong role of CET in formation of the dynamic features in the oscillating light. In the fast oscillations, both $\mathrm{Fd}$ and $\mathrm{PC}$ are becoming more reduced around the light maximum of 800 $\mu \mathrm{mol}\left(\right.$ photons) $\cdot \mathrm{m}^{-2} \cdot \mathrm{s}^{-1}$ when compared with the reference in the minimal light of $100 \mu \mathrm{mol}\left(\right.$ photons) $\cdot \mathrm{m}^{-2} \cdot \mathrm{s}^{-1}$.

Using the categorization of dynamic behavior introduced by Nedbal and Lazar in $2021^{7}$, the fast oscillations belong to the $\alpha_{2}$ a domain, the range at which the resonances occur to the $\alpha_{2} b$, and the slow oscillations to the $\beta_{2}$ a domain. The typical transients in these domains are shown, for $100-800 \mu \mathrm{mol}\left(\right.$ photons) $\cdot \mathrm{m}^{-2} \cdot \mathrm{s}^{-1}$, in detail in Supplementary Materials in Fig.SM-8. The dynamic behaviors in all intensities of light forcing in these domains are shown using the same color coding, blue for fast, green for the resonance, and red for

\footnotetext{
c The orientation of the period axis in Fig. 7 is, for the sake of better visualization, reversed in respect of the one in Fig.5 and 8 (red arrow).
} 
bioRxiv preprint doi: https://doi.org/10.1101/2022.02.09.479783; this version posted February 10, 2022. The copyright holder for this preprint (which was not certified by peer review) is the author/funder. All rights reserved. No reuse allowed without permission.

slow, also in Supplementary Materials Fig.SM-6 and in another format, from another perspective in Fig.SM9.

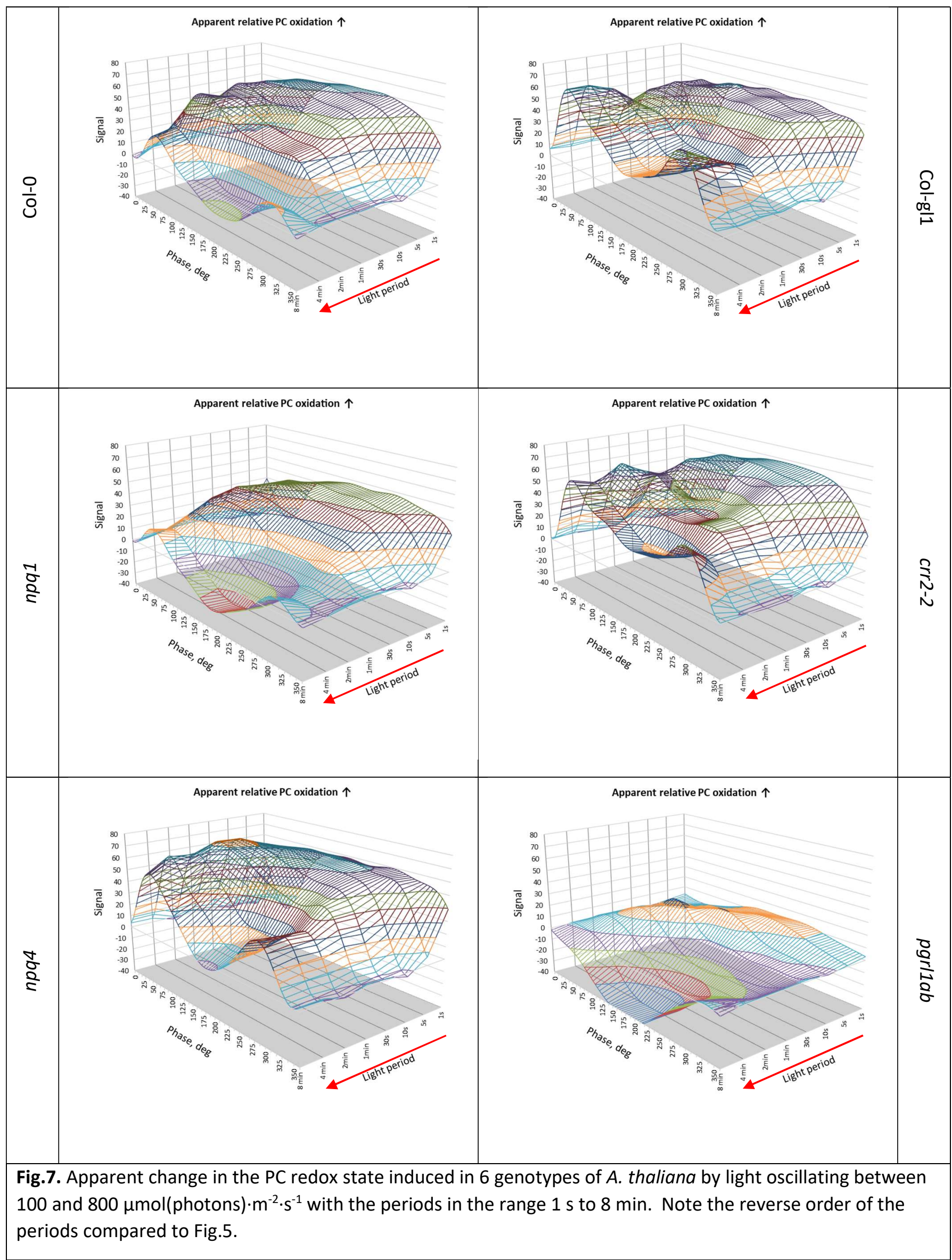


bioRxiv preprint doi: https://doi.org/10.1101/2022.02.09.479783; this version posted February 10, 2022. The copyright holder for this preprint (which was not certified by peer review) is the author/funder. All rights reserved. No reuse allowed without permission.

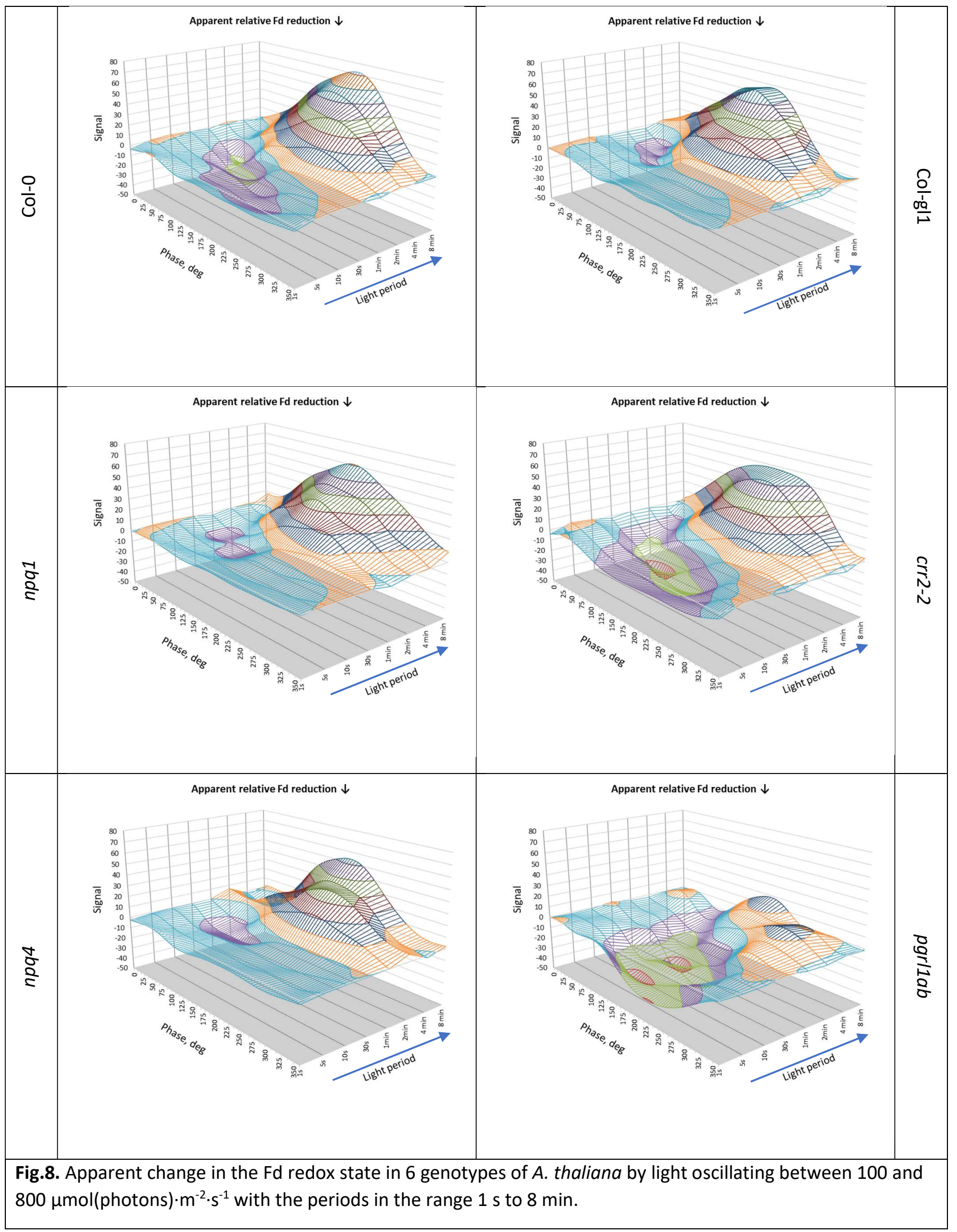




\section{Discussion}

The experiments identified two frequency domains: (1 to $1 / 30) \mathrm{Hz}$ and (1/60 to $1 / 480) \mathrm{Hz}$ in which photosynthesis exhibited distinct types of dynamic behavior in A.thaliana. The threshold range between these two domains (1/30 to $1 / 60) \mathrm{Hz}$ was marked by a resonance between the oscillating light and Chl-F yield that was dependent on the non-photochemical quenching (NPQ). In the faster frequency domain, NPQ of Chl-F was unable to follow the rapid light changes and the fluorescence emission variations were damped only to a small extent in WT and even less in the npq1 and npq4 mutants. In the slower frequency domain of the light oscillations, NPQ was very effective and reduced the variability of Chl-F yield much more in the WT than in the $n p q 1$ and npq4 mutants.

A very contrasting dynamic behavior of Chl-F yield was found in the pgrllab mutant, and to a smaller extent also in the crr2-2 mutant, that were incapacitated in the cyclic electron transport (CET). The variability of the Chl-F yield in oscillating light was, in these mutants, reduced both in the fast and slow light frequencies, qualitatively, in average not much different from WT. Interestingly, the variability of Chl-F yield was, in the pgrl1ab mutant, however anomalous in being larger in the slowly oscillating light and smaller in the fast oscillations.

We propose that the strong influence of CET on the dynamics of photosynthesis in our experiments may be explained when considering that the applied light was oscillating within a modest range (Tab.1) in which NPQ was activated but remained below or around $50 \%$ of the extreme values reported in literature ${ }^{69,87}$. NPQ was able to regulate the linear electron flow in the WTs and in the pgrl1ab and crr2-2 mutants so that Chl-F yield changes remained limited to a relatively narrow range. One can assume that with the effective NPQ regulation, the electron transport from PSII to PSI was relatively steady in spite of the strongly varying light. The light oscillations exerted, however, a strong impact on PSI photochemistry as witnessed by the largeamplitude oscillations in the P700 redox state in the WT. The dynamics of the PC, P700, Fd was, then, primarily dependent on the branching of the linear and cyclic electron transport in Photosystem I. With this, it was not surprising that the pgrl1ab mutant that is deficient in the major cyclic electron transport pathway was found exhibiting an anomalous dynamic behavior.

We argue that the dynamic de-coupling of the two photosystems and the strong modulation by the cyclic electron transport is further facilitated by the heterogeneity of the PQ poo ${ }^{88,89}$ : The PQ pool in the grana thylakoid domains participates in the linear electron transport from PSII to cyt $b_{6} f$ whereas the PQ pool in the stromal thylakoid domains serves primarily in the cyclic electron transport (see Fig.1). Further, one ought to consider that PC transports electrons from Cyt $b_{6} f$ to P700 over distance ${ }^{90}$, presumably with a low probability of backward electron transfer from P700 to PC and is subject to the photosynthesis control ${ }^{91}$.

We conclude that in the moderate light intensities and light fluctuation periods applied in our experiments and with NPQ fully functional, the most dynamic segment of the photosynthetic electron transport chain is in Photosystem I and that the cyclic electron flow largely dictates the overall dynamics.

The application potential of the photosynthetic forcing of plants by oscillating light can be deduced from the immense importance of the frequency-domain applications in physics and engineering. New terrain is however entered here, because most of the physical systems that are routinely characterized by sinusoidal stimulation are linear. In linear systems, a superposition of multiple sinusoidal modes, as it occurs in randomly fluctuating stimulation, can be predicted as an arithmetical sum of responses to the constituent single oscillatory modes. This is not necessarily true in plants that are non-linear. Thus, the plant responses to a dark-to-light transition and to the superposition of harmonic oscillatory modes that represent elemental 
Fourier decomposition of such a dark-to-light transition may differ from each other because of the inherent non-linearity of photosynthesis. If the difference would be found negligible, the frequency-domain analysis presented here and in the earlier papers ${ }^{7,84}$ would yield identical information as the time-domain measurements, albeit without requiring the usual dark acclimation and offering a higher sensitivity. If the difference would be found large, the time-domain and frequency-domain experiments would yield a complementary information: The time domain an information about plants in a transition from dark to light and the frequency domain about plants in light. The non-equivalence of the frequency- and time-domain data may open a possibility that the frequency-domain sensing can be more potent in the early detection of plant stresses than the conventional time-domain sensing ${ }^{93-95}$.

\section{References}

1 Billah, K. Y. \& Scanlan, R. H. Resonance, Tacoma Narrows Bridge Failure, and Undergraduate Physics Textbooks. American Journal of Physics 59, 118-124, doi:10.1119/1.16590 (1991).

2 Gutierrez Soto, M. \& Adeli, H. Tuned Mass Dampers. Archives of Computational Methods in Engineering 20, 419-431, doi:10.1007/s11831-013-9091-7 (2013).

3 Pospíšil, P. Production of Reactive Oxygen Species by Photosystem II. Biochim. Biophys. Acta, Bioenerg. 1787, 1151-1160, doi:10.1016/j.bbabio.2009.05.005 (2009).

4 Lima-Melo, Y. et al. Photoinhibition of Photosystem I Provides Oxidative Protection During Imbalanced Photosynthetic Electron Transport in Arabidopsis thaliana. Front Plant Sci 10, 916, doi:10.3389/fpls.2019.00916 (2019).

5 Sellier, D. \& Fourcaud, T. Crown Structure and Wood Properties: Influence on Tree Sway and Response to High Winds. Am J Bot 96, 885-896, doi:10.3732/ajb.0800226 (2009).

6 Nedbal, L. \& Březina, V. Complex Metabolic Oscillations in Plants Forced by Harmonic Irradiance. Biophysical Journal 83, 2180-2189, doi:10.1016/S0006-3495(02)73978-7 (2002).

7 Nedbal, L. \& Lazár, D. Photosynthesis Dynamics and Regulation Sensed in the Frequency Domain. Plant Physiol 187, 646-661, doi:10.1093/plphys/kiab317 (2021).

8 Li, X. P., Muller-Moule, P., Gilmore, A. M. \& Niyogi, K. K. PsbS-dependent Enhancement of Feedback DeExcitation Protects Photosystem II from Photoinhibition. Proceedings of the National Academy of Sciences of the United States of America 99, 15222-15227, doi:10.1073/pnas.232447699 (2002).

9 Johnson, M. P. \& Ruban, A. V. Arabidopsis Plants Lacking PsbS Protein Possess Photoprotective Energy Dissipation. Plant J 61, 283-289, doi:10.1111/j.1365-313X.2009.04051.x (2010).

10 Roach, T. \& Krieger-Liszkay, A. The Role of the PsbS Protein in the Protection of Photosystems I and II against High Light in Arabidopsis thaliana. Biochim. Biophys. Acta, Bioenerg. 1817, 2158-2165, doi:10.1016/j.bbabio.2012.09.011 (2012).

11 Demmig-Adams, B., Adams, W. W., Garab, G. \& Govindjee. Non-Photochemical Quenching and Energy Dissipation in Plants, Algae and Cyanobacteria Preface. Vol. 40 (Springer Netherlands, 2014).

Ruban, A. V. Nonphotochemical Chlorophyll Fluorescence Quenching: Mechanism and Effectiveness in Protecting Plants from Photodamage. Plant Physiology 170, 1903-1916, doi:10.1104/pp.15.01935 (2016).

Ware, M. A., Belgio, E. \& Ruban, A. V. Comparison of the Protective Effectiveness of NPQ in Arabidopsis Plants Deficient in PsbS Protein and Zeaxanthin. J Exp Bot 66, 1259-1270, doi:10.1093/jxb/eru477 (2015).

Kulheim, C., Agren, J. \& Jansson, S. Rapid Regulation of Light Harvesting and Plant Fitness in the Field. Science 297, 91-93, doi:10.1126/science.1072359 (2002).

Alter, P., Dreissen, A., Luo, F. L. \& Matsubara, S. Acclimatory Responses of Arabidopsis to Fluctuating Light Environment: Comparison of Different Sunfleck Regimes and Accessions. Photosynthesis Research 113, 221237, doi:10.1007/s11120-012-9757-2 (2012).

Steen, C. J., Morris, J. M., Short, A. H., Niyogi, K. K. \& Fleming, G. R. Complex Roles of PsbS and Xanthophylls in the Regulation of Nonphotochemical Quenching in Arabidopsis thaliana under Fluctuating Light. Journal of Physical Chemistry B 124, 10311-10325, doi:10.1021/acs.jpcb.0c06265 (2020). to Naturally and Artificially Fluctuating Light Conditions. Plant Cell 24, 2934-2948, doi:10.1105/tpc.112.097162 (2012). 
bioRxiv preprint doi: https://doi.org/10.1101/2022.02.09.479783; this version posted February 10, 2022. The copyright holder for this preprint (which was not certified by peer review) is the author/funder. All rights reserved. No reuse allowed without permission.

Wang, C. J., Yamamoto, H. \& Shikanai, T. Role of Cyclic Electron Transport around Photosystem I in Regulating Proton Motive Force. Biochim. Biophys. Acta, Bioenerg. 1847, 931-938, doi:10.1016/j.bbabio.2014.11.013 (2015).

Yamori, W., Makino, A. \& Shikanai, T. A Physiological Role of Cyclic Electron Transport around Photosystem I in Sustaining Photosynthesis under Fluctuating Light in Rice. Sci Rep 6, 20147, doi:10.1038/srep20147 (2016). Yamori, W. Photosynthetic Response to Fluctuating Environments and Photoprotective Strategies under Abiotic Stress. Journal of Plant Research 129, 379-395, doi:10.1007/s10265-016-0816-1 (2016).

Shimakawa, G. \& Miyake, C. Changing Frequency of Fluctuating Light Reveals the Molecular Mechanism for P700 Oxidation in Plant Leaves. Plant Direct 2, e00073, doi:10.1002/pld3.73 (2018).

Nakano, H., Yamamoto, H. \& Shikanai, T. Contribution of NDH-dependent Cyclic Electron Transport around Photosystem I to the Generation of Proton Motive Force in the Weak Mutant Allele of pgr5. Biochim. Biophys. Acta, Bioenerg. 1860, 369-374, doi:10.1016/j.bbabio.2019.03.003 (2019).

Yamamoto, H. \& Shikanai, T. PGR5-Dependent Cyclic Electron Flow Protects Photosystem I under Fluctuating Light at Donor and Acceptor Sides. Plant Physiology 179, 588-600, doi:10.1104/pp.18.01343 (2019).

Huang, W., Yang, S. J., Zhang, S. B., Zhang, J. L. \& Cao, K. F. Cyclic Electron Flow Plays an Important Role in Photoprotection for the Resurrection Plant Paraboea rufescens under Drought Stress. Planta 235, 819-828, doi:10.1007/s00425-011-1544-3 (2012).

Nedbal L., Červený J., Schmidt H. (2009) Scaling and Integration of Kinetic Models of Photosynthesis: Towards Comprehensive E-Photosynthesis. In: Laisk A., Nedbal L., Govindjee (eds) Photosynthesis in silico. Advances in Photosynthesis and Respiration, vol 29. Springer, Dordrecht. https://doi.org/10.1007/978-14020-9237-4_2.

Roden, J. S. \& Pearcy, R. W. Effect of Leaf Flutter on the Light Environment of Poplars. Oecologia 93, 201-207, doi: 10.1007/Bf00317672 (1993).

Smith, W. K. \& Berry, Z. C. Sunflecks? Tree Physiol 33, 233-237, doi:10.1093/treephys/tpt005 (2013). 1996).

Chazdon, R. L. \& Pearcy, R. W. The Importance of Sunflecks for Forest Understory Plants - Photosynthetic Machinery Appears Adapted to Brief, Unpredictable Periods of Radiation. Bioscience 41, 760-766, doi:10.2307/1311725 (1991).

Dera, J. \& Gordon, H. R. Light Field Fluctuations in the Photic Zone. Limnology and Oceanography 13, 697-699, doi:10.4319/lo.1968.13.4.0697 (1968).

Walsh, P. \& Legendre, L. Photosynthesis of Natural Phytoplankton under High-Frequency Light Fluctuations Simulating Those Induced by Sea-Surface Waves. Limnology and Oceanography 28, 688-697, doi:10.4319/lo.1983.28.4.0688 (1983).

32 de Langre, E. Effects of Wind on Plants. Annual Review of Fluid Mechanics 40, 141-168, doi:10.1146/annurev.fluid.40.111406.102135 (2008).

Pearcy, R. W., Roden, J. S. \& Gamon, J. A. Sunfleck Dynamics in Relation to Canopy Structure in a Soybean (Glycine-Max (L) Merr) Canopy. Agricultural and Forest Meteorology 52, 359-372, doi:10.1016/01681923(90)90092-K (1990).

Peressotti, A., Marchiol, L. \& Zerbi, G. Photosynthetic Photon Flux Density and Sunfleck Regime within Canopies of Wheat, Sunflower and Maize in Different Wind Conditions. Italian Journal of Agronomy 4, 87-92 (2001).

Knapp, A. K. \& Smith, W. K. Stomatal and Photosynthetic Responses during Sun/Shade Transitions in Subalpine Plants: Influence on Water Use Efficiency. Oecologia 74, 62-67, doi:10.1007/bf00377346 (1987).

Kaiser, E., Morales, A. \& Harbinson, J. Fluctuating Light Takes Crop Photosynthesis on a Rollercoaster Ride. Plant Physiology 176, 977-989, doi:10.1104/pp.17.01250 (2018).

Way, D. A. \& Pearcy, R. W. Sunflecks in Trees and Forests: from Photosynthetic Physiology to Global Change Biology. Tree Physiol 32, 1066-1081, doi:10.1093/treephys/tps064 (2012).

Dera, J., Sagan, S. \& Stramski, D. Focusing of Sunlight by Sea-Surface Waves - New Measurement Results from the Black-Sea. Optics of the Air-Sea Interface : Theory and Measurement 1749, 65-72 (1993). Morales, A. \& Kaiser, E. Photosynthetic Acclimation to Fluctuating Irradiance in Plants. Front Plant Sci 11, 268, doi:10.3389/fpls.2020.00268 (2020).

Navrátil, M., Špunda, V., Marková, I. \& Janouš, D. Spectral Composition of Photosynthetically Active Radiation Penetrating into a Norway Spruce Canopy: the Opposite Dynamics of the Blue/Red Spectral Ratio during Clear and Overcast Days. Trees-Structure and Function 21, 311-320, doi:10.1007/s00468-007-0124-4 (2007). 
bioRxiv preprint doi: https://doi.org/10.1101/2022.02.09.479783; this version posted February 10, 2022. The copyright holder for this preprint (which was not certified by peer review) is the author/funder. All rights reserved. No reuse allowed without permission.

Schenck, H. On the Focusing of Sunlight by Ocean Waves. Journal of the Optical Society of America 47, 653657, doi:10.1364/Josa.47.000653 (1957).

Li, X. P. et al. A Pigment-Binding Protein Essential for Regulation of Photosynthetic Light Harvesting. Nature 403, 391-395, doi:10.1038/35000131 (2000).

Niyogi, K. K., Grossman, A. R. \& Bjorkman, O. Arabidopsis Mutants Define a Central Role for the Xanthophyll Cycle in the Regulation of Photosynthetic Energy Conversion. Plant Cell 10, 1121-1134, doi:10.1105/tpc.10.7.1121 (1998).

Hashimoto, M., Endo, T., Peltier, G., Tasaka, M. \& Shikanai, T. A Nucleus-Encoded Factor, CRR2, is Essential for the Expression of Chloroplast ndhB in Arabidopsis. Plant J 36, 541-549, doi:10.1046/j.1365-313X.2003.01900.x (2003).

Munekaga, Y. et al. Cyclic Electron Flow around Photosystem I is Essential for Photosynthesis. Nature 429, 579582, doi:10.1038/nature02598 (2004).

DalCorso, G. et al. A Complex Containing PGRL1 and PGR5 is Involved in the Switch between Linear and Cyclic Electron Flow in Arabidopsis. Cell 132, 273-285, doi:10.1016/j.cell.2007.12.028 (2008). de Bianchi, S., Ballottari, M., Dall'osto, L. \& Bassi, R. Regulation of Plant Light Harvesting by Thermal Dissipation of Excess Energy. Biochem Soc Trans 38, 651-660, doi:10.1042/BST0380651 (2010).

Li, X. P., Gilmore, A. M. \& Niyogi, K. K. Molecular and Global Time-Resolved Analysis of a psbS Gene Dosage Effect on pH- and Xanthophyll Cycle-Dependent Nonphotochemical Quenching in Photosystem II. Journal of Biological Chemistry 277, 33590-33597, doi:10.1074/jbc.M204797200 (2002).

Horton, P. \& Ruban, A. Molecular Design of the Photosystem II Light-Harvesting Antenna: Photosynthesis and Photoprotection. J Exp Bot 56, 365-373, doi:10.1093/jxb/eri023 (2005).

Holzwarth, A. R., Miloslavina, Y., Nilkens, M. \& Jahns, P. Identification of Two Quenching Sites Active in the Regulation of Photosynthetic Light-Harvesting Studied by Time-Resolved Fluorescence. Chem Phys Lett 483, 262-267, doi:10.1016/j.cplett.2009.10.085 (2009). Ruban, A. V. Evolution under the
doi:10.1093/jxb/eru400 (2015).

Murchie, E. H. \& Ruban, A. V. Dynamic Non-Photochemical Quenching in Plants: From Molecular Mechanism to Productivity. Plant J 101, 885-896, doi:10.1111/tpj.14601 (2020).

Shikanai, T. Central Role of Cyclic Electron Transport around Photosystem I in the Regulation of Photosynthesis. Curr Opin Biotechnol 26, 25-30, doi:10.1016/j.copbio.2013.08.012 (2014).

Hertle, A. P. et al. PGRL1 Is the Elusive Ferredoxin-Plastoquinone Reductase in Photosynthetic Cyclic Electron Flow. Molecular Cell 49, 511-523, doi:10.1016/j.molcel.2012.11.030 (2013).

Sugimoto, K. et al. A Single Amino Acid Alteration in PGR5 Confers Resistance to Antimycin A in Cyclic Electron Transport around PSI. Plant and Cell Physiology 54, 1525-1534, doi:10.1093/pcp/pct098 (2013).

Munekage, Y. et al. PGR5 is Involved in cyclic Electron Flow around Photosystem I and is Essential for Photoprotection in Arabidopsis. Cell 110, 361-371, doi:10.1016/S0092-8674(02)00867-X (2002).

Suorsa, M. et al. PGR5 Ensures Photosynthetic Control to Safeguard Photosystem I under Fluctuating Light Conditions. Plant Signal Behav 8, e22741, doi:10.4161/psb.22741 (2013).

Peltier, G., Aro, E. M. \& Shikanai, T. NDH-1 and NDH-2 Plastoquinone Reductases in Oxygenic Photosynthesis. Annual Review of Plant Biology, Vol 67 67, 55-80, doi:10.1146/annurev-arplant-043014-114752 (2016). Yamamoto, H., Peng, L., Fukao, Y. \& Shikanai, T. An Src Homology 3 Domain-like Fold Protein Forms a Ferredoxin Binding Site for the Chloroplast NADH Dehydrogenase-like Complex in Arabidopsis. Plant Cell 23, 1480-1493, doi:10.1105/tpc.110.080291 (2011).

Fisher, N. \& Kramer, D. M. Non-Photochemical Reduction of Thylakoid Photosynthetic Redox Carriers in vitro: Relevance to Cyclic Electron Flow around Photosystem I? Biochim. Biophys. Acta, Bioenerg. 1837, 1944-1954, doi:10.1016/j.bbabio.2014.09.005 (2014).

Strand, D. D., Fisher, N. \& Kramer, D. M. The Higher Plant Plastid NAD(P)H Dehydrogenase-like Complex (NDH) is a High Efficiency Proton Pump that increases ATP Production by Cyclic Electron Flow. Journal of Biological Chemistry 292, 11850-11860, doi:10.1074/jbc.M116.770792 (2017).

Fisher, N., Bricker, T. M. \& Kramer, D. M. Regulation of Photosynthetic Cyclic Electron Flow Pathways by Adenylate Status in Higher Plant Chloroplasts. Biochim. Biophys. Acta, Bioenerg. 1860, 148081, doi:10.1016/j.bbabio.2019.148081 (2019).

Laughlin, T. G., Savage, D. F. \& Davies, K. M. Recent Advances on the Structure and Function of NDH-1: The Complex I of Oxygenic Photosynthesis. Biochim. Biophys. Acta, Bioenerg. 1861, 148254, doi:10.1016/j.bbabio.2020.148254 (2020). 
bioRxiv preprint doi: https://doi.org/10.1101/2022.02.09.479783; this version posted February 10, 2022. The copyright holder for this preprint (which was not certified by peer review) is the author/funder. All rights reserved. No reuse allowed without permission.

Parey, K., Wirth, C., Vonck, J. \& Zickermann, V. Respiratory Complex I - Structure, Mechanism and Evolution. Curr Opin Struct Biol 63, 1-9, doi:10.1016/j.sbi.2020.01.004 (2020).

Klughammer, C. \& Schreiber, U. Deconvolution of Ferredoxin, Plastocyanin, and P700 Transmittance Changes in Intact Leaves with a New Type of Kinetic LED Array Spectrophotometer. Photosynth Res 128, 195-214, doi:10.1007/s11120-016-0219-0 (2016).

Schreiber, U. Redox Changes of Ferredoxin, P700, and Plastocyanin Measured Simultaneously in Intact Leaves. Photosynth Res 134, 343-360, doi:10.1007/s11120-017-0394-7 (2017).

Holzwarth, A. R. \& Jahns, P. Non-Photochemical Quenching Mechanisms in Intact Organisms as Derived from Ultrafast-Fluorescence Kinetic Studies. Adv Photosynth Resp 40, 129-156, doi:10.1007/978-94-017-9032-1_5 (2014).

Dall'Osto, L., Cazzaniga, S., Wada, M. \& Bassi, R. On the Origin of a Slowly Reversible Fluorescence Decay Component in the Arabidopsis npq4 Mutant. Philos Trans $R$ Soc Lond B Biol Sci 369, 20130221, doi:10.1098/rstb.2013.0221 (2014).

Kress, E. \& Jahns, P. The Dynamics of Energy Dissipation and Xanthophyll Conversion in Arabidopsis Indicate an Indirect Photoprotective Role of Zeaxanthin in Slowly Inducible and Relaxing Components of Nonphotochemical Quenching of Excitation Energy. Front Plant Sci 8, 2094, doi:10.3389/fpls.2017.02094 (2017). Okegawa, Y., Kagawa, Y., Kobayashi, Y. \& Shikanai, T. Characterization of Factors Affecting the Activity of Photosystem I Cyclic Electron Transport in Chloroplasts. Plant and Cell Physiology 49, 825-834, doi:10.1093/pcp/pcn055 (2008).

Okegawa, Y. \& Motohashi, K. M-Type Thioredoxins Regulate the PGR5/PGRL1-Dependent Pathway by Forming a Disulfide-Linked Complex with PGRL1. Plant Cell 32, 3866-3883, doi:10.1105/tpc.20.00304 (2020).

Yadav, R. M., Aslam, S. M., Madireddi, S. K., Chouhan, N. \& Subramanyam, R. Role of Cyclic Electron Transport Mutations pgrl1 and pgr5 in Acclimation Process to High Light in Chlamydomonas reinhardtii. Photosynth Res 146, 247-258, doi:10.1007/s11120-020-00751-w (2020).

Takizawa, K., Cruz, J. A., Kanazawa, A. \& Kramer, D. M. The Thylakoid Proton Motive Force in vivo. Quantitative, Non-Invasive Probes, Energetics, and Regulatory Consequences of Light-Induced pmf. Biochim. Biophys. Acta, Bioenerg. 1767, 1233-1244, doi:10.1016/j.bbabio.2007.07.006 (2007).

Zaks, J., Amarnath, K., Kramer, D. M., Niyogi, K. K. \& Fleming, G. R. A Kinetic Model of Rapidly Reversible Nonphotochemical Quenching. Proc Natl Acad Sci U S A 109, 15757-15762, doi:10.1073/pnas.1211017109 (2012).

Nilkens, M. et al. Identification of a Slowly Inducible Zeaxanthin-Dependent Component of Non-Photochemical Quenching of Chlorophyll Fluorescence Generated under Steady-State Conditions in Arabidopsis. BbaBioenergetics 1797, 466-475, doi:10.1016/j.bbabio.2010.01.001 (2010).

Setif, P., Boussac, A. \& Krieger-Liszkay, A. Near-Infrared in vitro Measurements of Photosystem I Cofactors and Electron-Transfer Partners with a Recently Developed Spectrophotometer. Photosynth Res 142, 307-319, doi:10.1007/s11120-019-00665-2 (2019).

77 Bilger, W. \& Björkman, O. Role of the Xanthophyll Cycle in Photoprotection Elucidated by Measurements of Light-Induced Absorbance Changes, Fluorescence and Photosynthesis in Leaves of Hedera canariensis. Photosynthesis Research 25, 173-185, doi:10.1007/BF00033159 (1990).

78 Bilger, W. \& Björkman, O. Relationships among Violaxanthin Deepoxidation, Thylakoid Membrane Conformation, and Nonphotochemical Chlorophyll Fluorescence Quenching in Leaves of Cotton (Gossypium hirsutum L.). Planta 193, 238-246, doi:10.1007/BF00192536 (1994).

Kouril, R. et al. Structural Characterization of a Plant Photosystem I and NAD(P)H Dehydrogenase Supercomplex. Plant J 77, 568-576, doi:10.1111/tpj.12402 (2014).

Ma, M. et al. The Physiological Functionality of PGR5/PGRL1-Dependent Cyclic Electron Transport in Sustaining Photosynthesis. Front Plant Sci 12, 702196, doi:10.3389/fpls.2021.702196 (2021).

Colombo, M. et al. Photosynthesis Control: An Underrated Short-Term Regulatory Mechanism Essential for Plant Viability. Plant Signal Behav 11, e1165382, doi:10.1080/15592324.2016.1165382 (2016).

$\mathrm{Li}, \mathrm{M}$. et al. Measuring the Dynamic Response of the Thylakoid Architecture in Plant Leaves by Electron Microscopy. Plant Direct 4, e00280, doi:10.1002/pld3.280 (2020).

Unnep, R. et al. Low-pH Induced Reversible Reorganizations of Chloroplast Thylakoid Membranes - As Revealed by Small-Angle Neutron Scattering. Biochim. Biophys. Acta, Bioenerg. 1858, 360-365, doi:10.1016/j.bbabio.2017.02.010 (2017). 
Nedbal, L., Březina, V., Červený, J. \& Trtílek, M. Photosynthesis in Dynamic Light: Systems Biology of Unconventional Chlorophyll Fluorescence Transients in Synechocystis sp. PCC 6803. Photosynth Res 84, 99106, doi:10.1007/s11120-004-6428-y (2005).

Delieu, T. J. \& Walker, D. A. Simultaneous Measurement of Oxygen Evolution and Chlorophyll Fluorescence from Leaf Pieces. Plant Physiology 73, 534-541, doi: 10.1104/pp.73.3.534 (1983).

Lazár, D., Kaňa, R., Klinkovský, T. \& Nauš, J. Experimental and Theoretical Study on High Temperature Induced Changes in Chlorophyll a Fluorescence Oscillations in Barley Leaves upon 2\% CO2. Photosynthetica 43, 13-27, doi: 10.1007/s11099-005-3027-x (2005).

87 Bonente, G., Howes, B. D., Caffarri, S., Smulevich, G. \& Bassi, R. Interactions between the Photosystem II Subunit PsbS and Xanthophylls Studied in vivo and in vitro. Journal of Biological Chemistry 283, 8434-8445, doi:10.1074/jbc.M708291200 (2008).

Joliot, P., Lavergne, J. \& Beal, D. Plastoquinone Compartmentation in Chloroplasts .1. Evidence for Domains with Different Rates of Photo-Reduction. Biochimica Et Biophysica Acta 1101, 1-12, doi:10.1016/01674838(92)90460-U (1992).

Kirchhoff, H., Horstmann, S. \& Weis, E. Control of the Photosynthetic Electron Transport by PQ Diffusion Microdomains in Thylakoids of Higher Plants. Biochim Biophys Acta 1459, 148-168, doi:10.1016/s00052728(00)00143-2 (2000).

Hohner, R. et al. Plastocyanin is the Long-Range Electron Carrier between Photosystem II and Photosystem I in Plants. Proceedings of the National Academy of Sciences of the United States of America 117, 15354-15362, doi:10.1073/pnas.2005832117 (2020).

Johnson, J. E. \& Berry, J. A. The Role of Cytochrome b6f in the Control of Steady-State Photosynthesis: a Conceptual and Quantitative Model. Photosynth Res 148, 101-136, doi:10.1007/s11120-021-00840-4 (2021). Lakowicz, J. R. Principles of fluorescence spectroscopy. (Springer science \& business media, 2013). Matouš, K., Benediktyová, Z., Berger, S., Roitsch, T. \& Nedbal, L. Case Study of Combinatorial Imaging: What Protocol and What Chlorophyll Fluorescence Image to use When Visualizing Infection of Arabidopsis thaliana by Pseudomonas syringae? Photosynth Res 90, 243-253, doi:10.1007/s11120-006-9120-6 (2006).

Berger, S. et al. Visualization of Dynamics of Plant-Pathogen Interaction by Novel Combination of Chlorophyll Fluorescence Imaging and Statistical Analysis: Differential Effects of Virulent and Avirulent Strains of $P$. syringae and of Oxylipins on A. thaliana. J Exp Bot 58, 797-806, doi:10.1093/jxb/erl208 (2007).

Pineda, M., Soukupová, J., Matouš, K., Nedbal, L. \& Baron, M. Conventional and Combinatorial Chlorophyll Fluorescence Imaging of Tobamovirus-Infected Plants. Photosynthetica 46, 441-451, doi:10.1007/s11099-0080076-y (2008). 


\title{
SUPPLEMENTARY MATERIALS
}

\section{THE DYNAMICS OF NON-PHOTOCHEMICAL QUENCHING AND CYCLIC ELECTRON TRANSPORT in A.THALIANA EXPOSED TO HARMONICALLY OSCILLATING LIGHT}

\author{
Niu Yuxi ${ }^{1}$, Lazár Dušan ${ }^{2}$, Holzwarth Alfred ${ }^{3}$, Kramer David M. ${ }^{4}$, \\ Matsubara Shizue ${ }^{1}$, Schrey Silvia D. ${ }^{1}$, Nedbal Ladislav ${ }^{1,2,5,{ }^{*}}$
}

${ }^{1}$ Institute of Bio- and Geosciences/Plant Sciences (IBG-2), Forschungszentrum Jülich, Wilhelm-JohnenStraße, D-52428 Jülich, Germany

2 Department of Biophysics, Centre of the Region Haná for Biotechnological and Agricultural Research, Faculty of Science, Palacký University, Šlechtitelů 27, 78371 Olomouc, Czech Republic

${ }^{3}$ Department of Physics and Astronomy, Faculty of Sciences, Vrije Universiteit Amsterdam, Amsterdam, The Netherlands

${ }^{4}$ MSU-DOE Plant Research Laboratory, Michigan State University, East Lansing, MI 48824, USA

${ }^{5}$ PASTEUR, Department of Chemistry, École Normale Supérieure, Université PSL, Sorbonne Université, CNRS, 24, rue Lhomond, 75005, Paris, France

${ }^{*}$ Corresponding author: nedbal.lad@gmail.com 
bioRxiv preprint doi: https://doi.org/10.1101/2022.02.09.479783; this version posted February 10, 2022. The copyright holder for this preprint (which was not certified by peer review) is the author/funder. All rights reserved. No reuse allowed without permission.

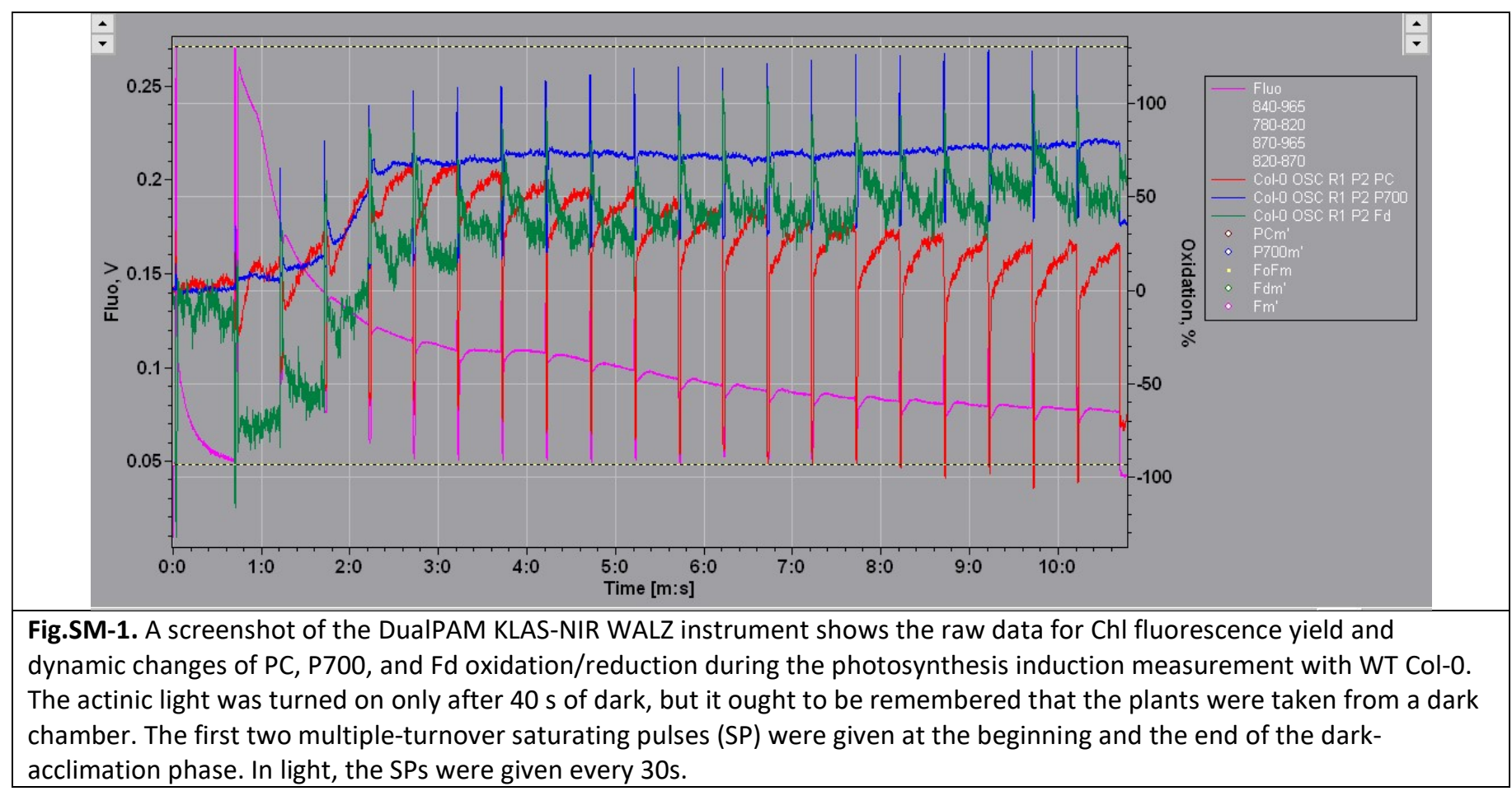




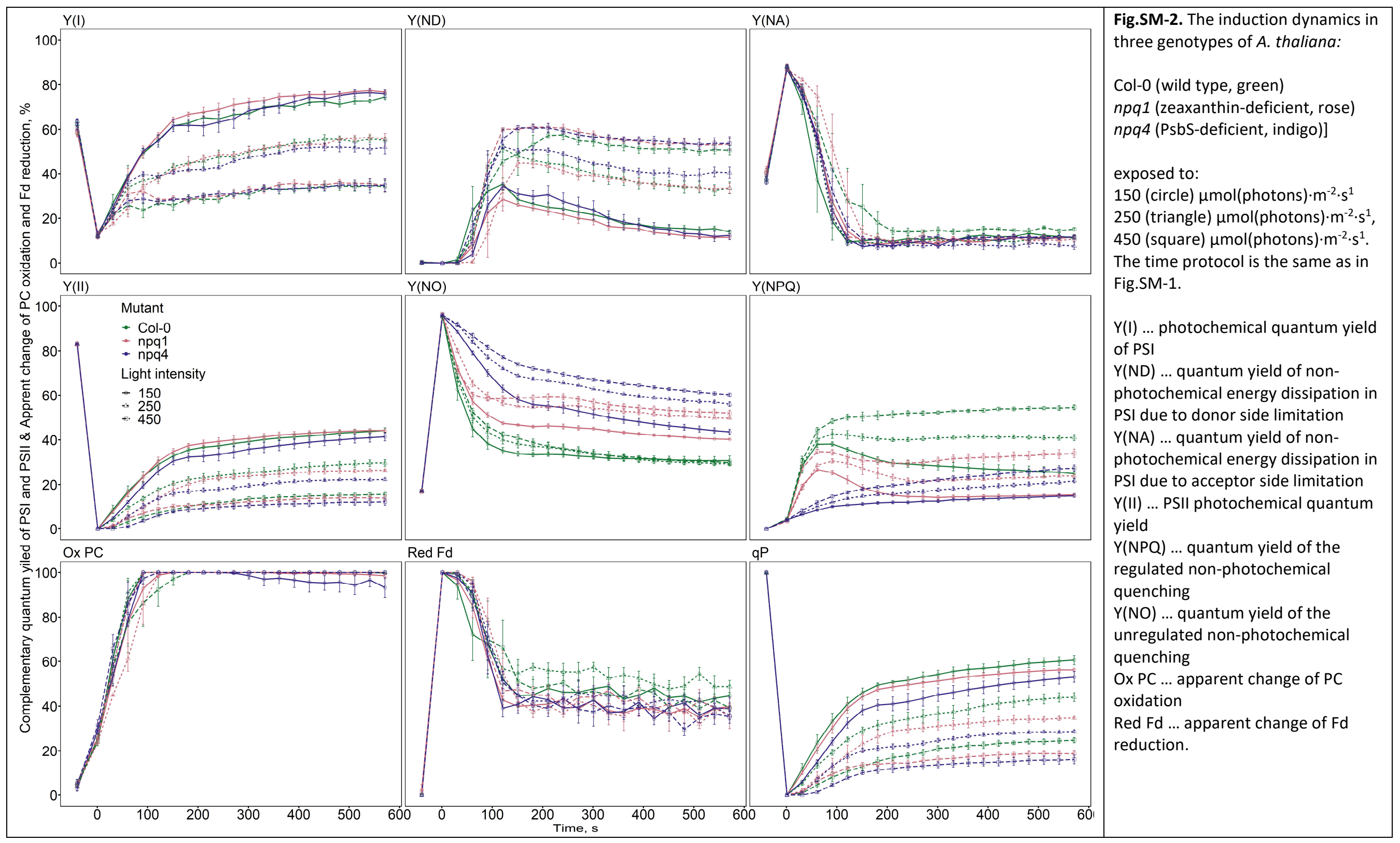

| SUPPLEMENTARY MATERIALS 


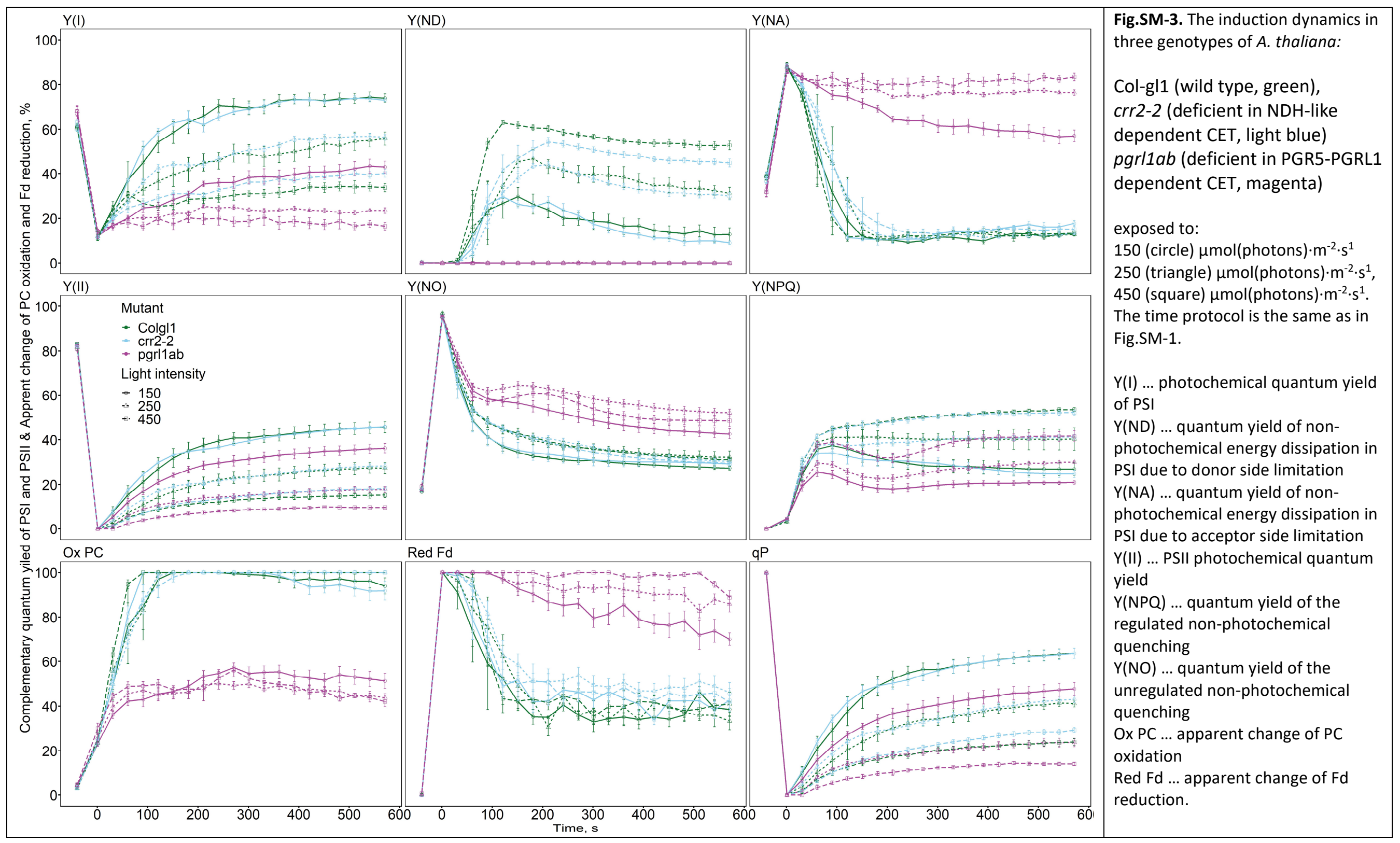

| SUPPLEMENTARY MATERIALS 


\begin{tabular}{|c|c|c|c|c|c|c|c|}
\hline & Genotype & Col-0 WT & $n p q 1$ & $n p q 4$ & Colgl1 WT & $c r r 2-2$ & pgrl1ab \\
\hline \multirow{3}{*}{ NPQ } & Low light & $0.86 \pm 0.1$ & $0.35 \pm 0.01$ & $0.30 \pm 0.01$ & $1 \pm 0.1$ & $0.9 \pm 0.1$ & $0.46 \pm 0.04$ \\
\hline & Med. light & $1.39 \pm 0.02$ & $0.45 \pm 0.01$ & $0.33 \pm 0.02$ & $1.2 \pm 0.2$ & $1.3 \pm 0.1$ & $0.53 \pm 0.03$ \\
\hline & High light & $1.71 \pm 0.03$ & $0.61 \pm 0.05$ & $0.39 \pm 0.02$ & $1.58 \pm 0.02$ & $1.66 \pm 0.06$ & $0.82 \pm 0.07$ \\
\hline \multirow{3}{*}{ plastocyanin } & Low light & $74 \pm 8$ & $64 \pm 8$ & $55 \pm 7$ & $62 \pm 6$ & $53 \pm 10$ & $28 \pm 7$ \\
\hline & Med. light & $45 \pm 11$ & $84 \pm 24$ & $63 \pm 13$ & $76 \pm 11$ & $73 \pm 8$ & $3 \pm 15$ \\
\hline & High light & $56 \pm 9$ & $47 \pm 7$ & $49 \pm 9$ & $52 \pm 2$ & $65 \pm 7$ & $-36 \pm 2$ \\
\hline \multirow{3}{*}{ P700 } & Low light & $20 \pm 5$ & $24 \pm 4$ & $31 \pm 11$ & $15 \pm 1$ & $25 \pm 3$ & $5 \pm 3$ \\
\hline & Med. light & $57 \pm 9$ & $43 \pm 17$ & $62 \pm 9$ & $43 \pm 7$ & $46 \pm 3$ & $9 \pm 7$ \\
\hline & High light & $71 \pm 6$ & $74 \pm 6$ & $79 \pm 8$ & $67 \pm 4$ & $57 \pm 5$ & $31 \pm 8$ \\
\hline \multirow{3}{*}{ ferredoxin } & Low light & $-18 \pm 6$ & $-32 \pm 13$ & $-45 \pm 25$ & $-18 \pm 12$ & $-13 \pm 3$ & $-33 \pm 14$ \\
\hline & Med. light & $-20 \pm 11$ & $-16 \pm 1$ & $-14 \pm 6$ & $-19 \pm 13$ & $-25 \pm 13$ & $-20 \pm 8$ \\
\hline & High light & $-12 \pm 3$ & $-10 \pm 2$ & $-12 \pm 5$ & $-28 \pm 19$ & $-25 \pm 9$ & $-14 \pm 3$ \\
\hline
\end{tabular}




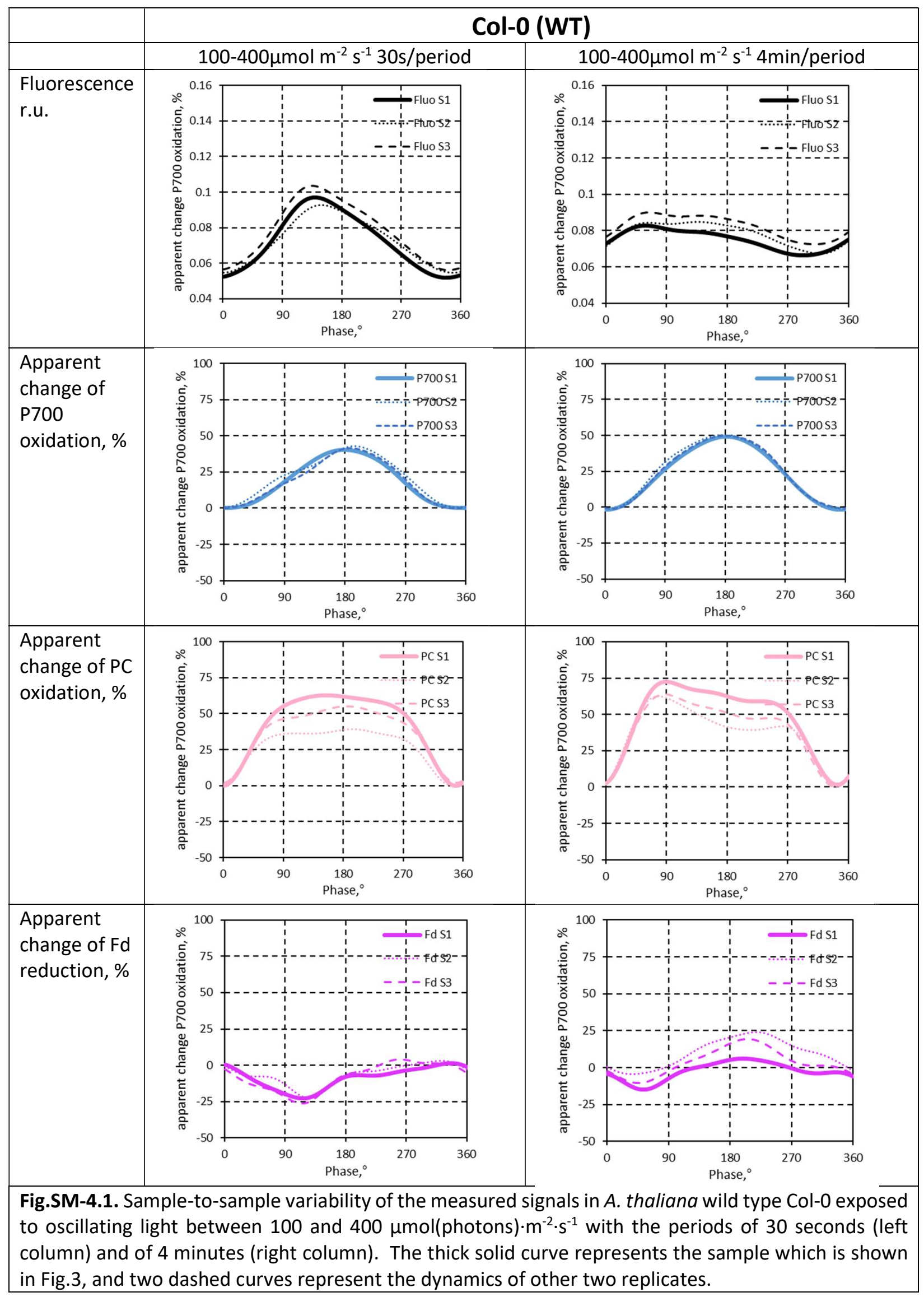


bioRxiv preprint doi: https://doi.org/10.1101/2022.02.09.479783; this version posted February 10,2022 . The copyright holder for this preprint (which was not certified by peer review) is the author/funder. All rights reserved. No reuse allowed without permission.

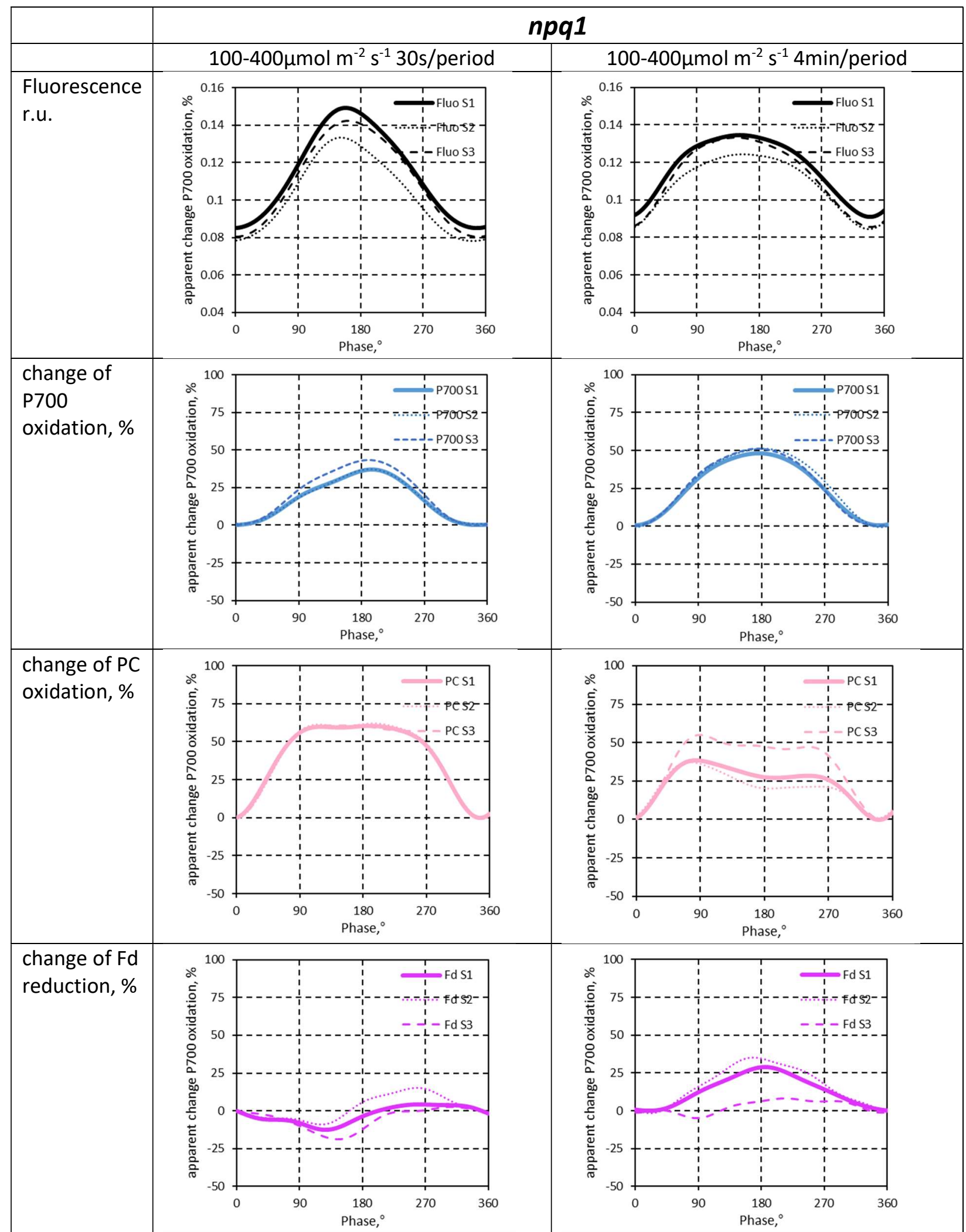

Fig.SM-4.2. Sample-to-sample variability of the measured signals in A. thaliana mutant npq1 (zeaxanthin-deficient). The experiment as in Fig.SM-4.1. 
bioRxiv preprint doi: https://doi.org/10.1101/2022.02.09.479783; this version posted February 10,2022 . The copyright holder for this preprint (which was not certified by peer review) is the author/funder. All rights reserved. No reuse allowed without permission.

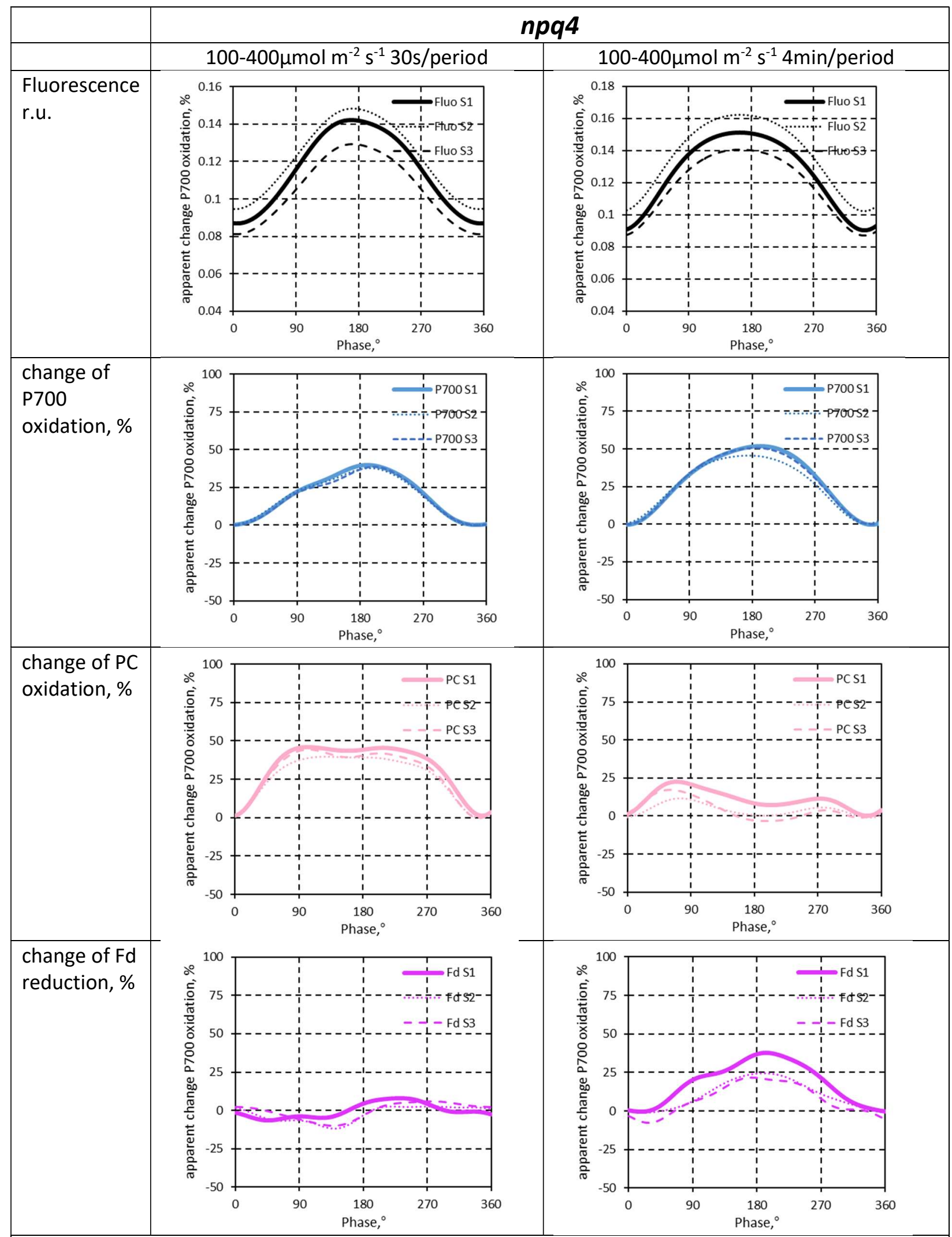

Fig.SM-4.3. Sample-to-sample variability of the measured signals in A. thaliana mutant $n p q 4$ (PsbSdeficient). The experiment as in Fig.SM-4.1. 
bioRxiv preprint doi: https://doi.org/10.1101/2022.02.09.479783; this version posted February 10,2022 . The copyright holder for this preprint (which was not certified by peer review) is the author/funder. All rights reserved. No reuse allowed without permission.

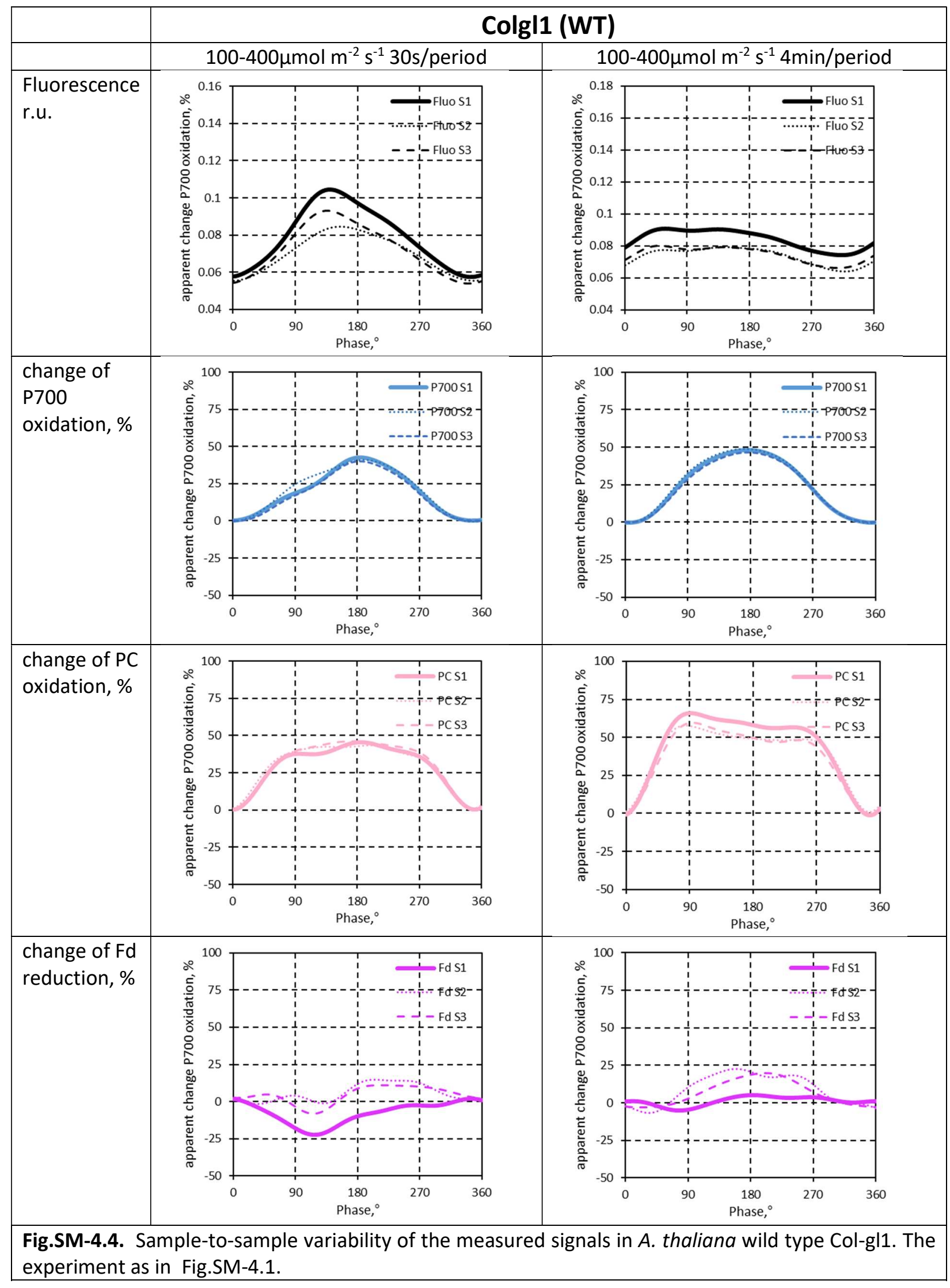


bioRxiv preprint doi: https://doi.org/10.1101/2022.02.09.479783; this version posted February 10,2022 . The copyright holder for this preprint (which was not certified by peer review) is the author/funder. All rights reserved. No reuse allowed without permission.

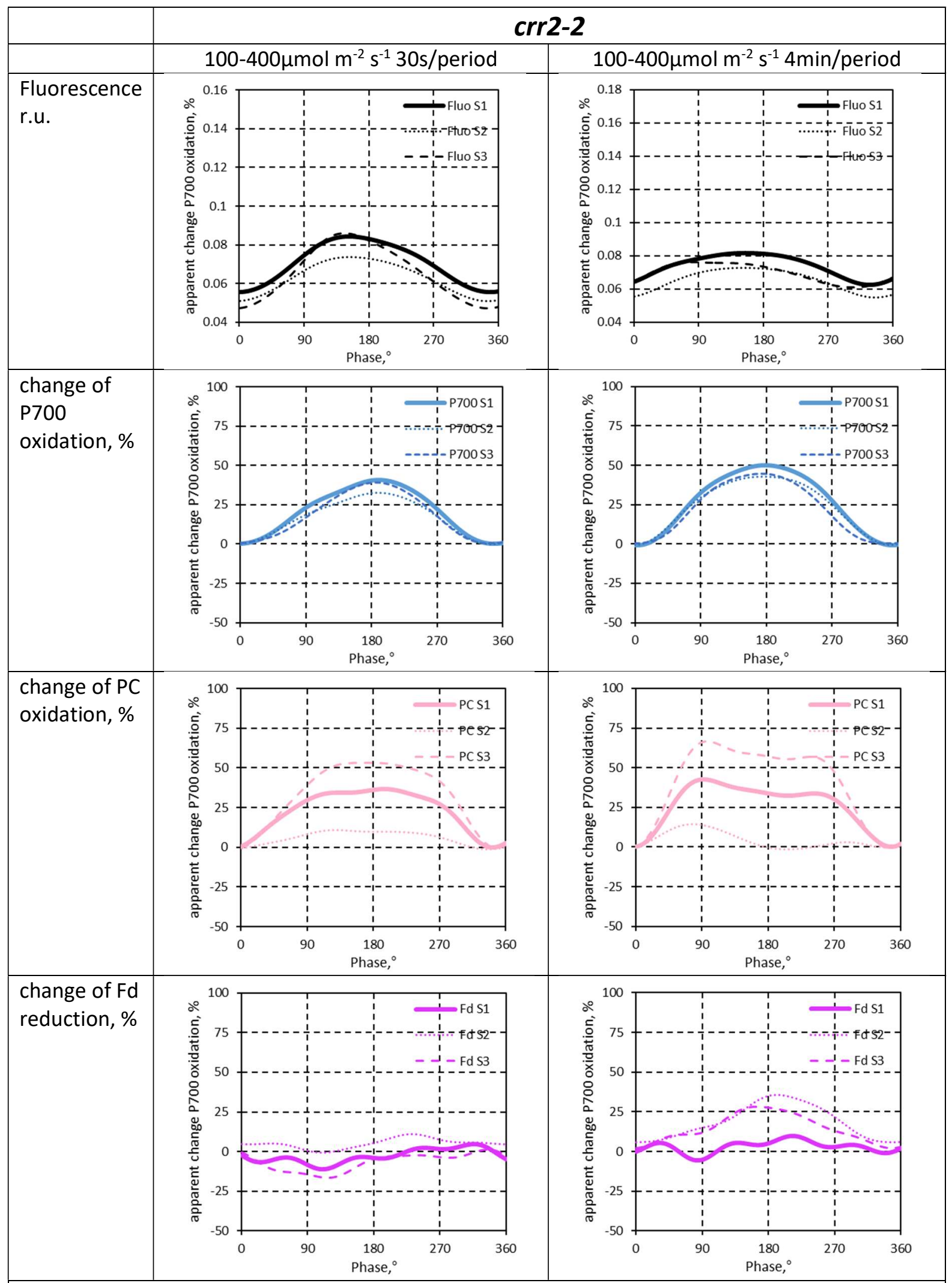

Fig.SM-4.5. Sample-to-sample variability of the measured signals in A. thaliana mutant crr2-2 (deficient in NDH-like dependent CET) . The experiment as in Fig.SM-4.1. 
bioRxiv preprint doi: https://doi.org/10.1101/2022.02.09.479783; this version posted February 10, 2022. The copyright holder for this preprint (which was not certified by peer review) is the author/funder. All rights reserved. No reuse allowed without permission.

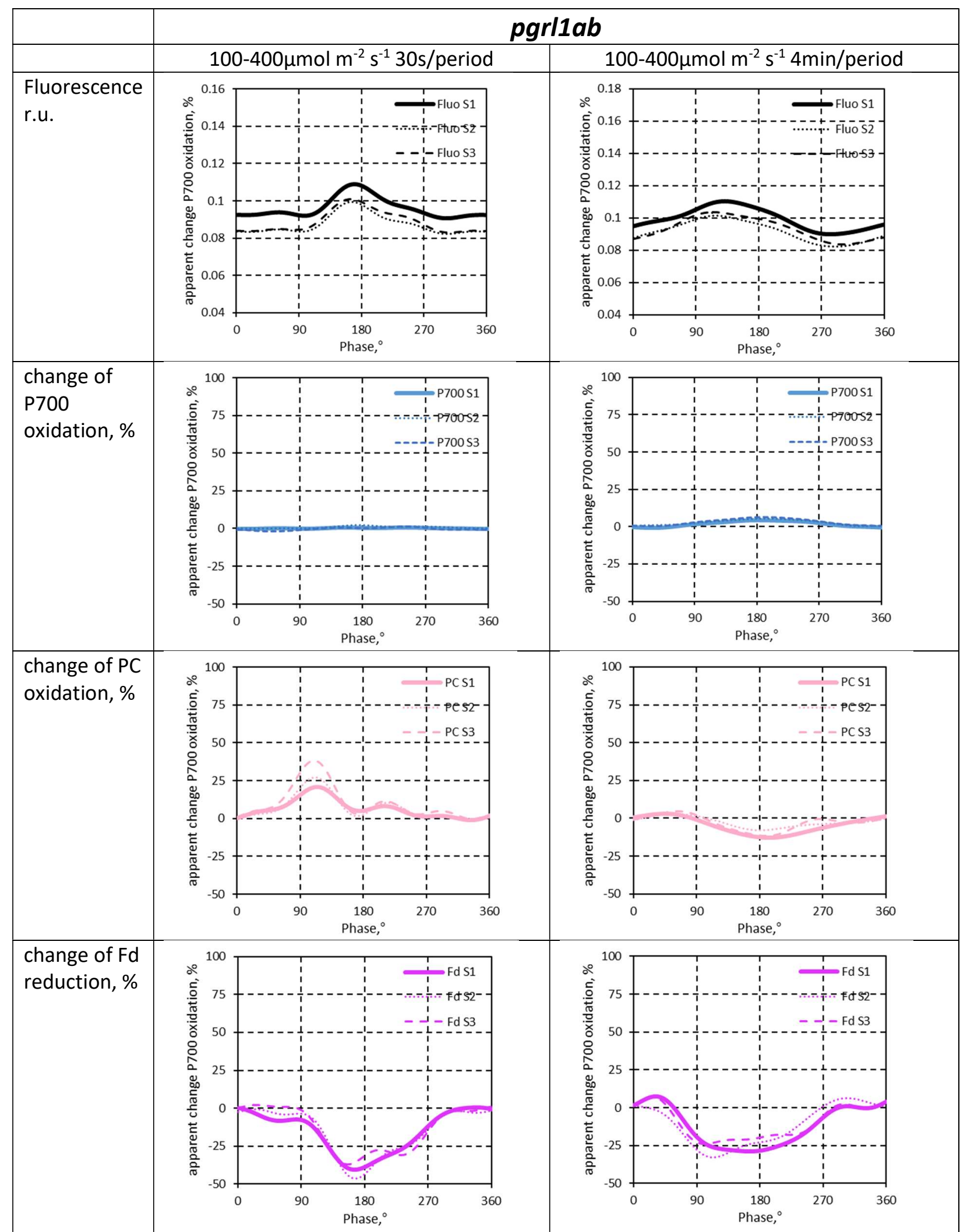

Fig.SM-4.6. Sample-to-sample variability of the measured signals in A. thaliana mutant pgrl1ab (deficient in PGR5-PGRL1 dependent CET). The experiment as in Fig.SM-4.1. 


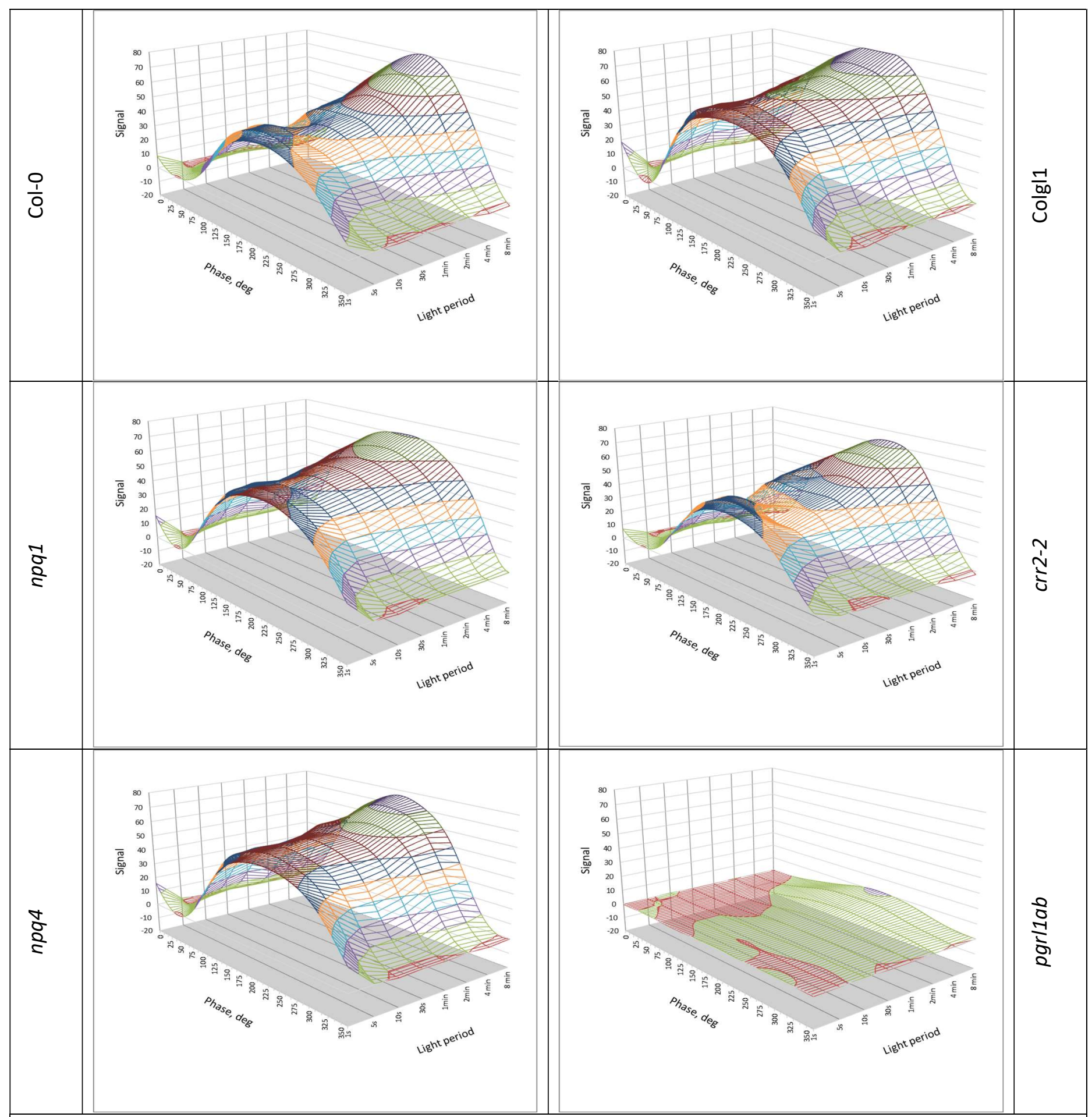

Fig.SM-5. The apparent change in the P700 redox state in 6 genotypes of A.thaliana by light oscillating between 100 and $800 \mu \mathrm{mol}$ (photons) $\cdot \mathrm{m}^{-2} \cdot \mathrm{s}^{-1}$ with the periods in the range $1 \mathrm{~s}$ to $8 \mathrm{~min}$. 

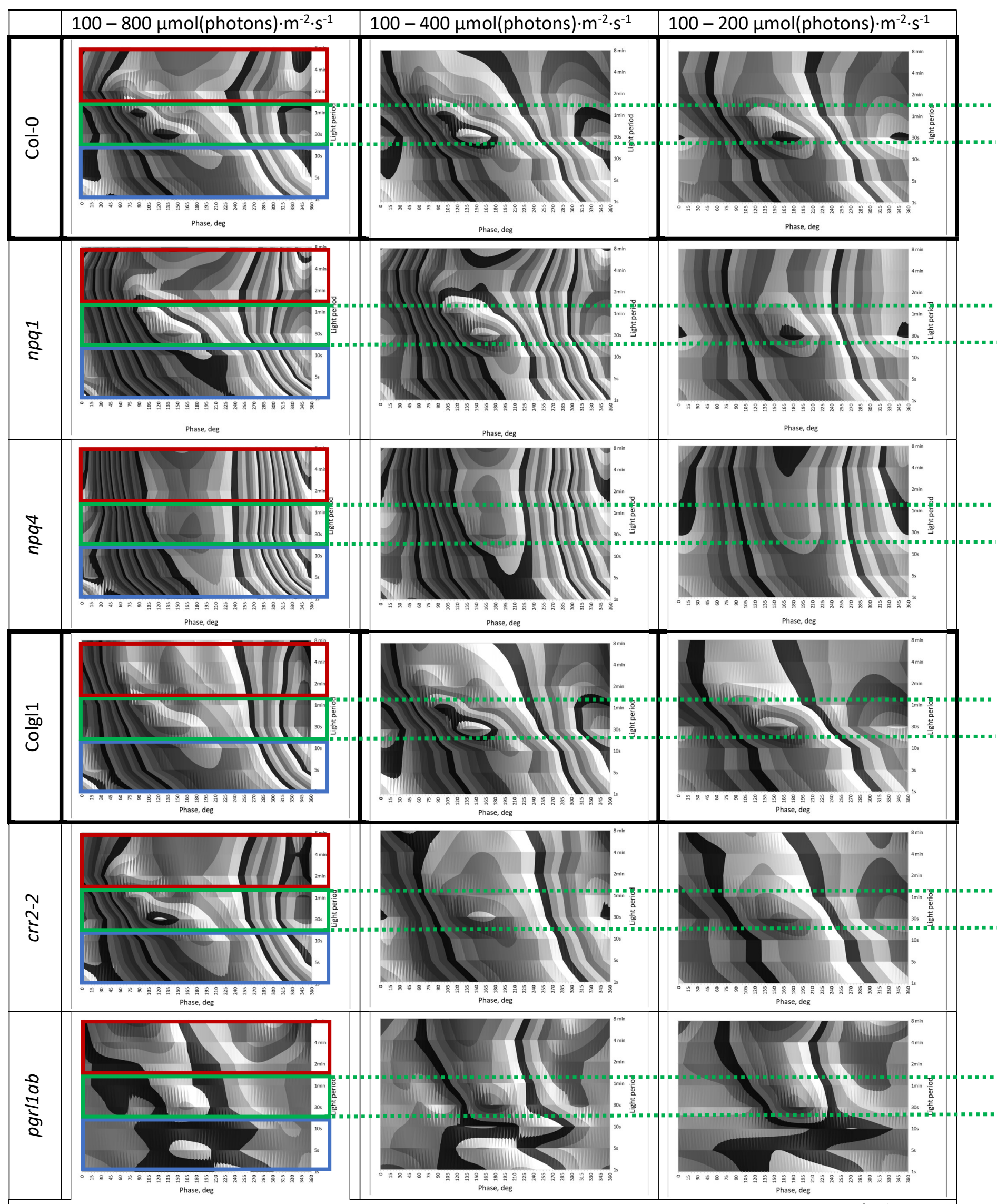

Fig.SM-6.1 The Chl-F yield dynamics in light that was oscillating between $100-800 \mu \mathrm{mol}\left(\right.$ photons) $\cdot \mathrm{m}^{-2} \cdot \mathrm{s}^{-1}, 100-$ $400 \mu \mathrm{mol}$ (photons) $\cdot \mathrm{m}^{-2} \cdot \mathrm{s}^{-1}$, and $100-200 \mu \mathrm{mol}$ (photons) $\cdot \mathrm{m}^{-2} \cdot \mathrm{s}^{-1}$ is shown for the 6 investigated genotypes.

The green color indicates the $\alpha_{2} b$ dynamic domain, red the $\beta_{2}$, and blue $\alpha_{2}$ a dynamic domain according to the nomenclature introduced in (Nedbal and Lazár 2021). 
bioRxiv preprint doi: https://doi.org/10.1101/2022.02.09.479783; this version posted February 10, 2022. The copyright holder for this preprint (which was not certified by peer review) is the author/funder. All rights reserved. No reuse allowed without permission.

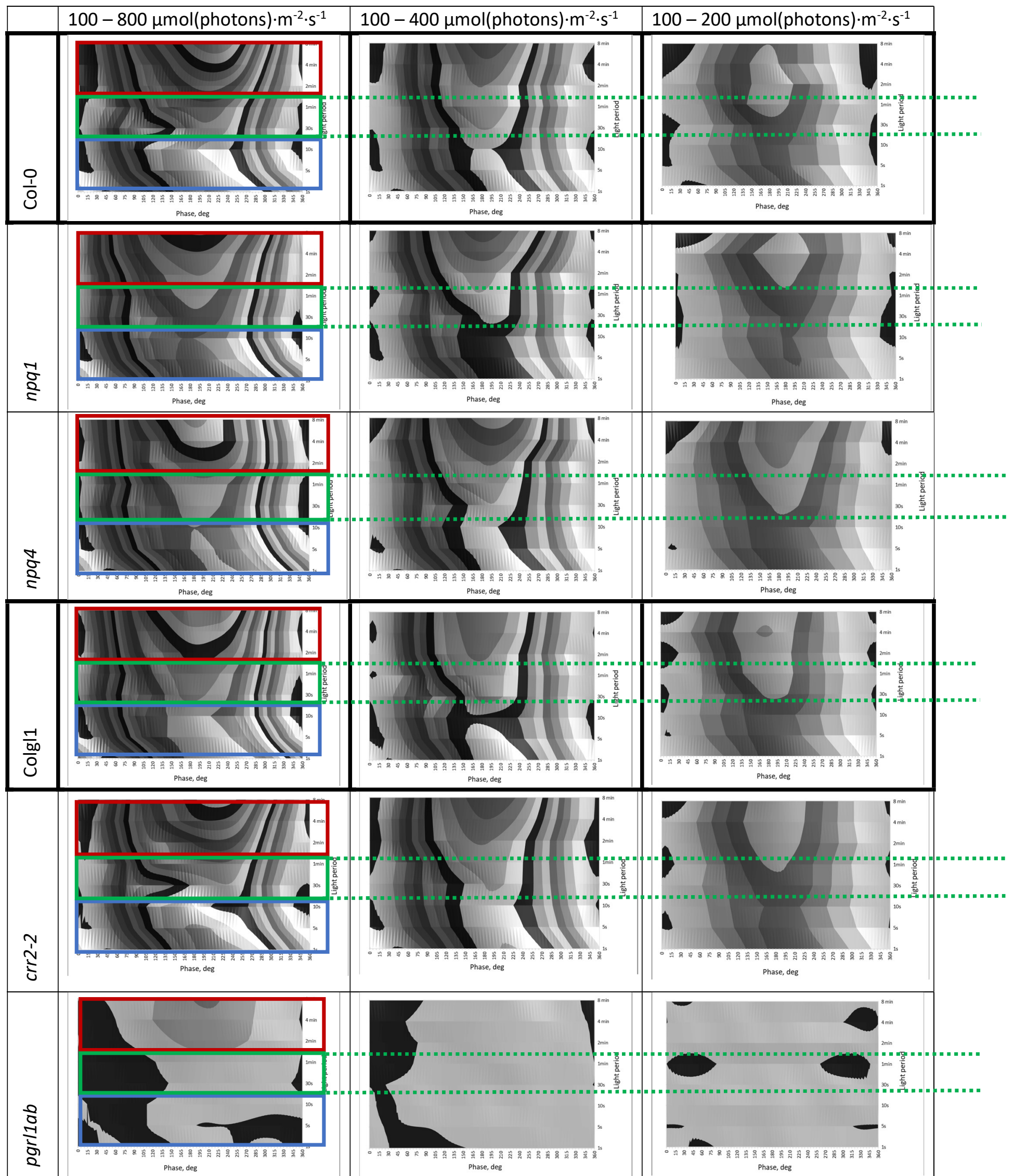

Fig.SM-6.2 The apparent relative P700 redox dynamics in light oscillating between $100-800 \mu \mathrm{mol}\left(\right.$ photons) $\cdot \mathrm{m}^{-}$ ${ }^{2} \cdot \mathrm{s}^{-1}, 100-400 \mu \mathrm{mol}\left(\right.$ photons) $\cdot \mathrm{m}^{-2} \cdot \mathrm{s}^{-1}$, and $100-200 \mu \mathrm{mol}$ (photons) $\cdot \mathrm{m}^{-2} \cdot \mathrm{s}^{-1}$ is shown for the 6 investigated genotypes. The green color indicates the $\alpha_{2} b$ dynamic domain, red the $\beta_{2}$, and blue $\alpha_{2}$ a dynamic domain according to the nomenclature introduced in (Nedbal and Lazár 2021). 
bioRxiv preprint doi: https://doi.org/10.1101/2022.02.09.479783; this version posted February 10, 2022. The copyright holder for this preprint (which was not certified by peer review) is the author/funder. All rights reserved. No reuse allowed without permission.

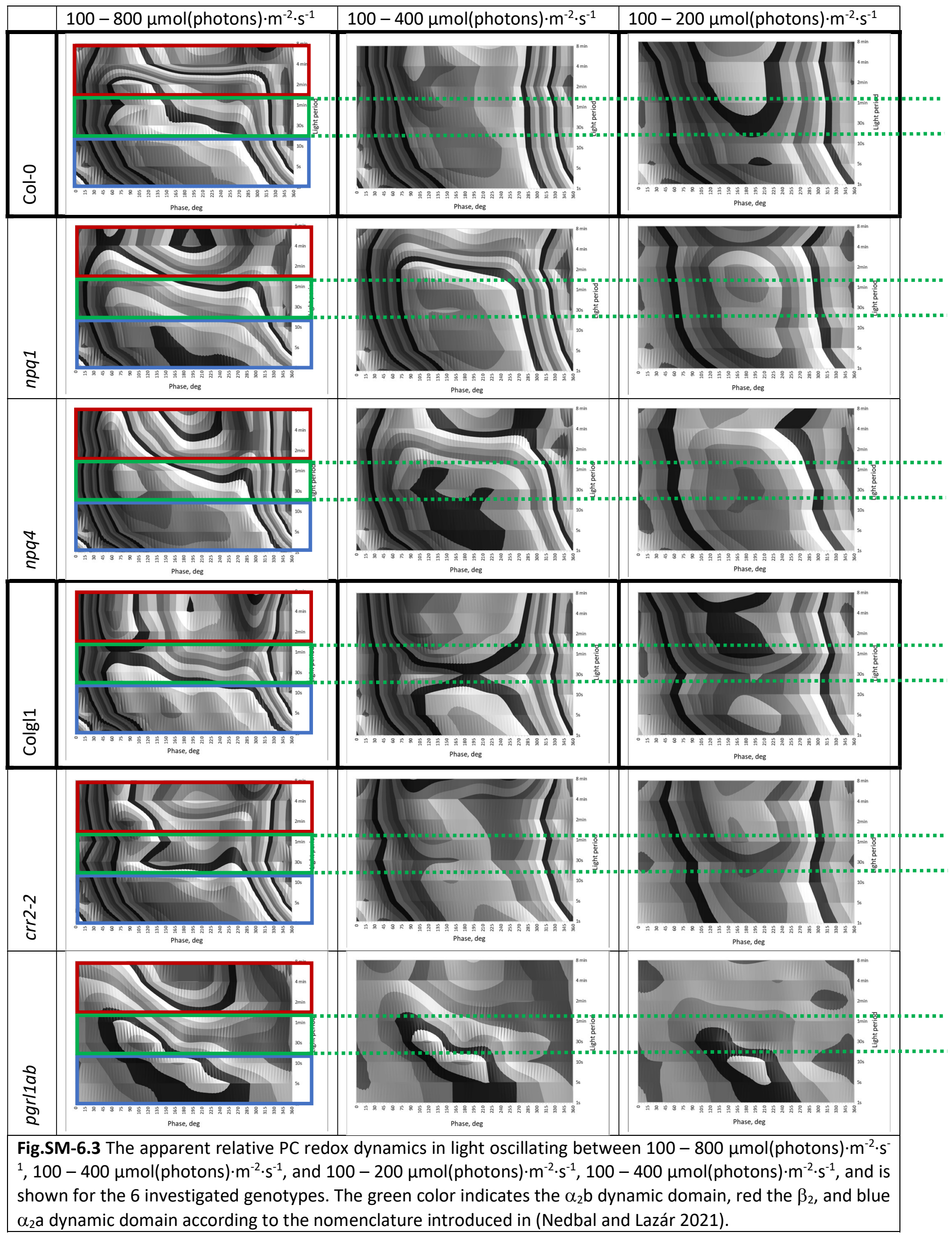


bioRxiv preprint doi: https://doi.org/10.1101/2022.02.09.479783; this version posted February 10, 2022. The copyright holder for this preprint (which was not certified by peer review) is the author/funder. All rights reserved. No reuse allowed without permission.

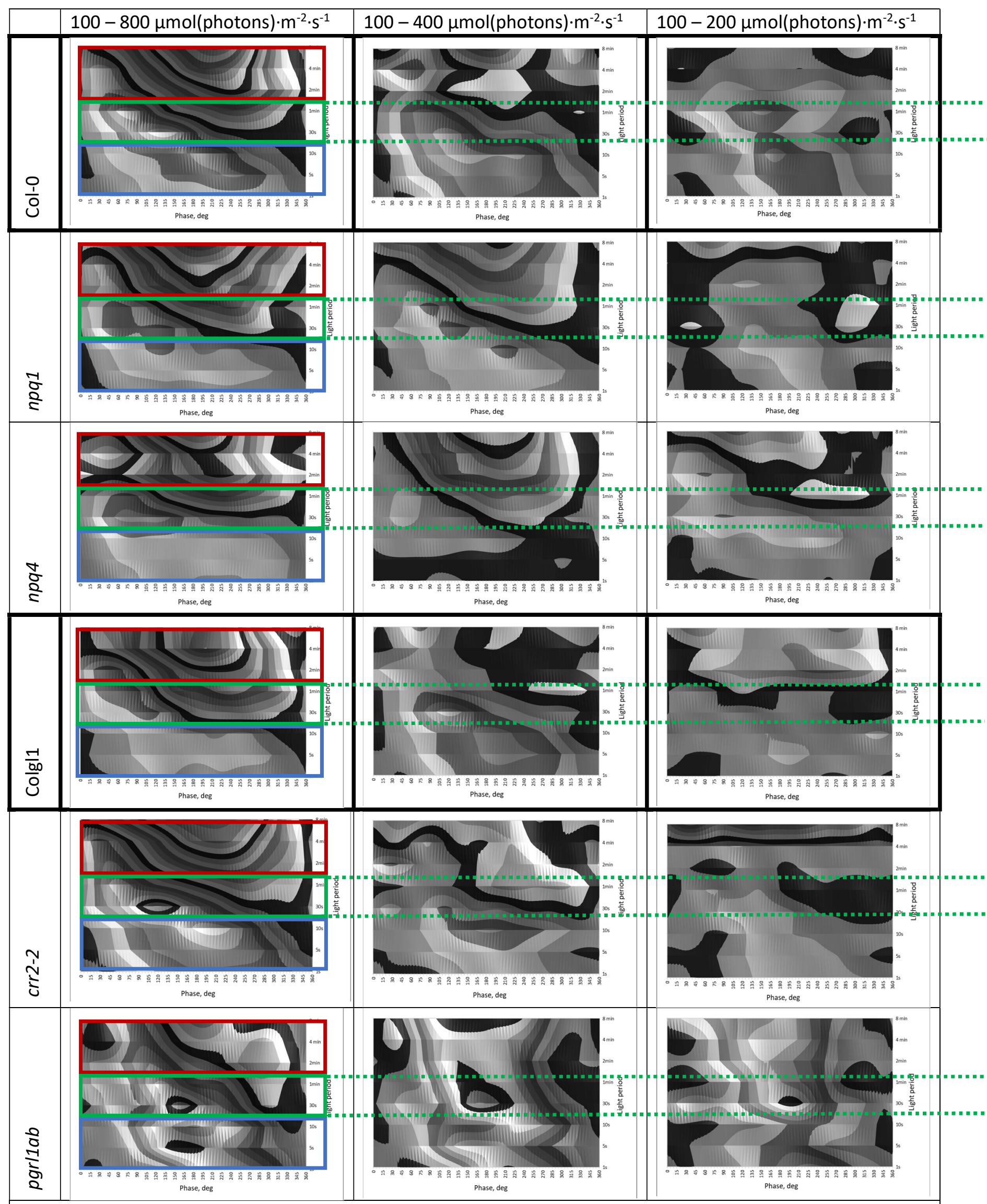

Fig.SM-6.4 The apparent relative Fd-related signal in light oscillating between $100-800 \mu \mathrm{mol}\left(\right.$ photons) $\cdot \mathrm{m}^{-2} \cdot \mathrm{s}^{-1}$, $100-400 \mu \mathrm{mol}$ (photons) $\cdot \mathrm{m}^{-2} \cdot \mathrm{s}^{-1}$, and $100-200 \mu \mathrm{mol}$ (photons) $\cdot \mathrm{m}^{-2} \cdot \mathrm{s}^{-1}$ is shown for the 6 investigated genotypes. The green color indicates the $\alpha_{2} b$ dynamic domain, red the $\beta_{2}$, and blue $\alpha_{2}$ a dynamic domain according to the nomenclature introduced in (Nedbal and Lazár 2021). 
bioRxiv preprint doi: https://doi.org/10.1101/2022.02.09.479783; this version posted February 10, 2022. The copyright holder for this preprint (which was not certified by peer review) is the author/funder. All rights reserved. No reuse allowed without permission.

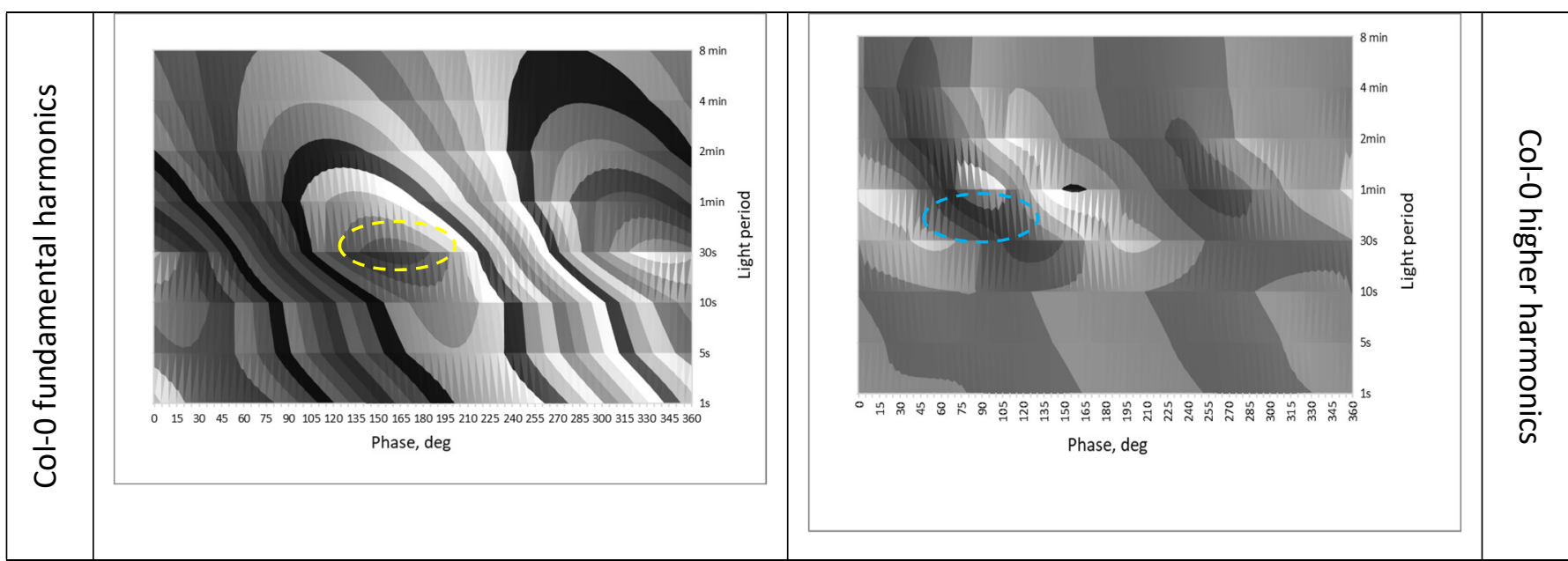

Fig.SM-7. The fundamental harmonics and all upper harmonic components of the time-variable part of the Chl$F$ yield induced WT Col- 0 of $A$. thaliana by light oscillating between 100 and $400 \mu \mathrm{mol}\left(\right.$ photons) $\cdot \mathrm{m}^{-2} \cdot \mathrm{s}^{-1}$ with the periods in the range $1 \mathrm{~s}$ to $8 \mathrm{~min}$. 
bioRxiv preprint doi: https://doi.org/10.1101/2022.02.09.479783; this version posted February 10, 2022. The copyright holder for this preprint (which was not certified by peer review) is the author/funder. All rights reserved. No reuse allowed without permission.

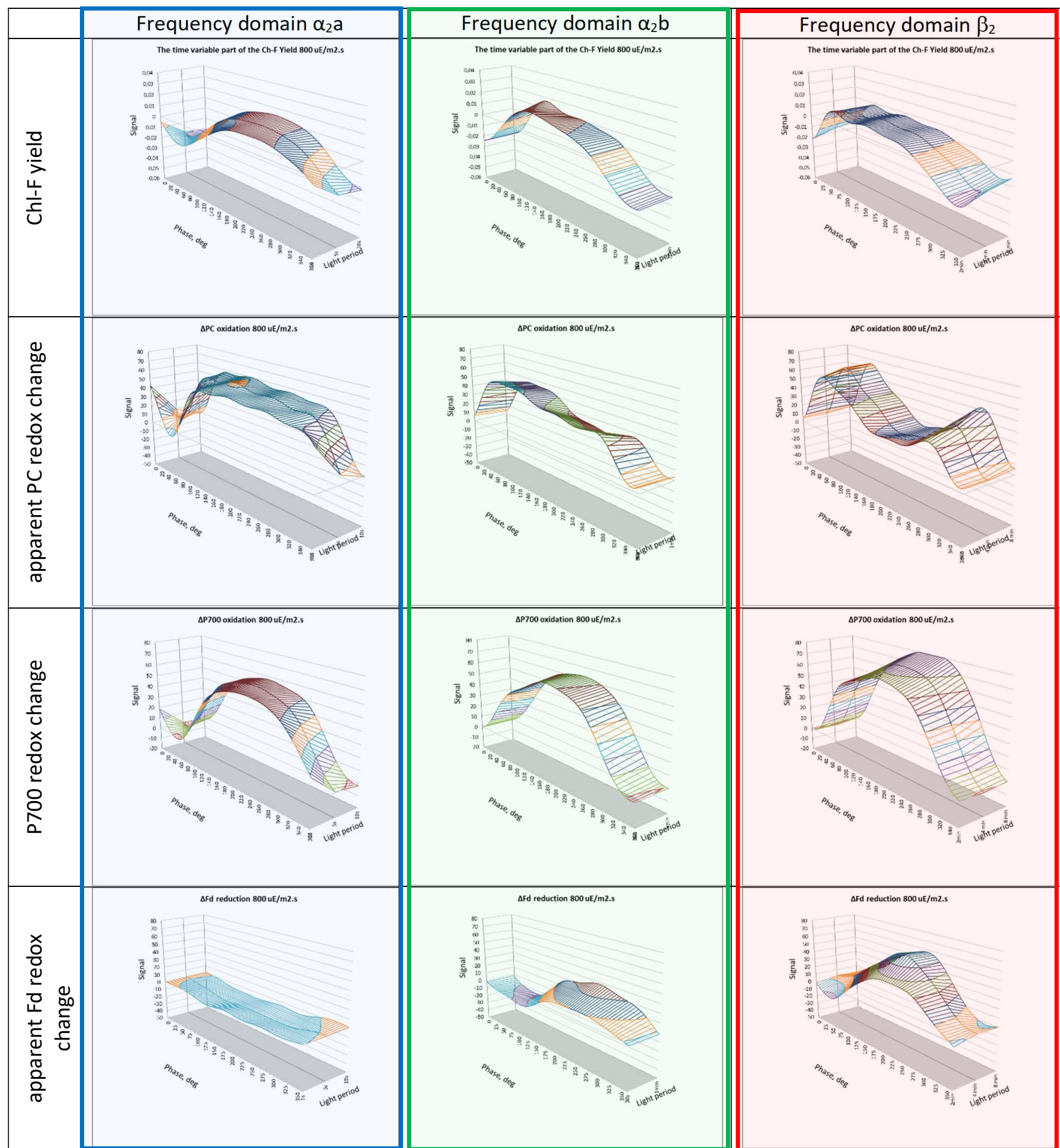

Fig.SM-8. Categorization into three frequency domains illustrated on the signals obtained with the Colgl1 wildtype in light oscillating between $100-800 \mu \mathrm{mol}\left(\right.$ photons) $\cdot \mathrm{m}^{-2} \cdot \mathrm{s}^{-1}$. 
bioRxiv preprint doi: https://doi.org/10.1101/2022.02.09.479783; this version posted February 10, 2022. The copyright holder for this preprint (which was not certified by peer review) is the author/funder. All rights reserved. No reuse allowed without permission.

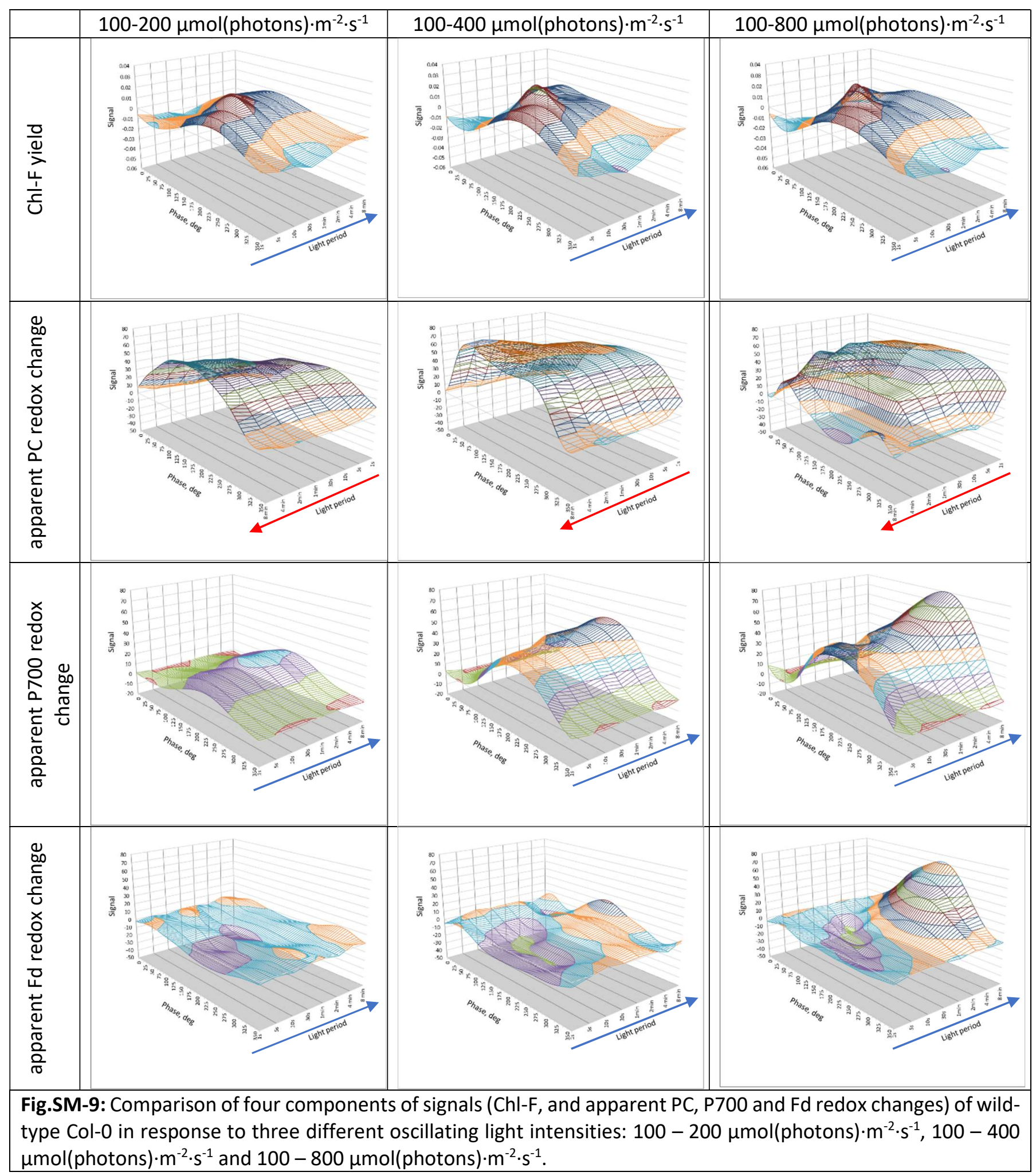

